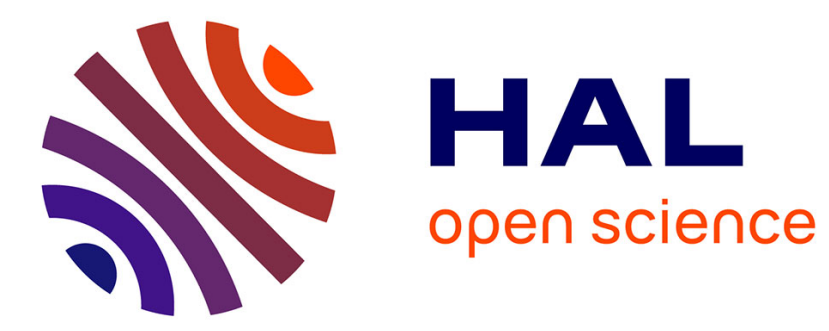

\title{
Building SSPs for Climate Policy Analysis: A Scenario Elicitation Methodology to Map the Space of Possible Future Challenges to Mitigation and Adaptation
}

\author{
Julie Rozenberg, Céline Guivarch, R.J. Lempert, Stéphane Hallegatte
}

\section{- To cite this version:}

Julie Rozenberg, Céline Guivarch, R.J. Lempert, Stéphane Hallegatte. Building SSPs for Climate Policy Analysis: A Scenario Elicitation Methodology to Map the Space of Possible Future Challenges to Mitigation and Adaptation. 2012. hal-00793927

\section{HAL Id: hal-00793927 \\ https: / hal-enpc.archives-ouvertes.fr/hal-00793927}

Preprint submitted on 24 Feb 2013

HAL is a multi-disciplinary open access archive for the deposit and dissemination of scientific research documents, whether they are published or not. The documents may come from teaching and research institutions in France or abroad, or from public or private research centers.
L'archive ouverte pluridisciplinaire HAL, est destinée au dépôt et à la diffusion de documents scientifiques de niveau recherche, publiés ou non, émanant des établissements d'enseignement et de recherche français ou étrangers, des laboratoires publics ou privés. 
FONDAZIONE ENI

ENRICO MATTEI

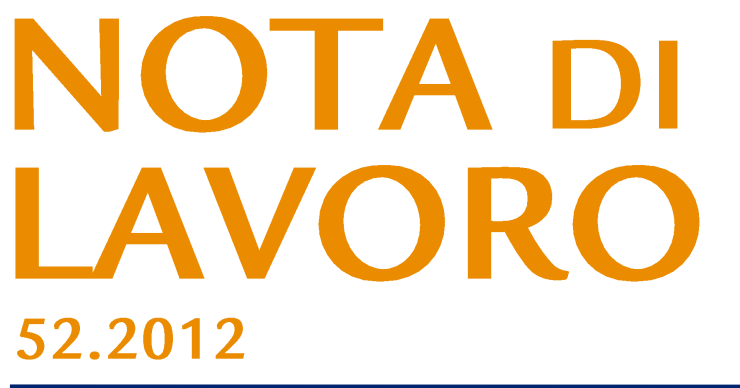

Building SSPs for Climate Policy Analysis: A Scenario Elicitation Methodology to Map the Space of Possible Future Challenges to Mitigation and Adaptation

By Julie Rozenberg, CIRED

Céline Guivarch, CIRED

Robert Lempert, RAND Corporation, Santa Monica Office

Stéphane Hallegatte, World Bank and Météo France 


\section{Climate Change and Sustainable Development Series}

Editor: Carlo Carraro

\section{Building SSPs for Climate Policy Analysis: A Scenario Elicitation Methodology to Map the Space of Possible Future Challenges to Mitigation and Adaptation \\ By Julie Rozenberg, CIRED}

Céline Guivarch, CIRED

Robert Lempert, RAND Corporation, Santa Monica Office

Stéphane Hallegatte, World Bank and Météo France

\section{Summary}

The scientific community is now developing a new set of scenarios, referred to as Shared Socio-economic Pathways (SSPs) to replace the SRES scenarios. To be used to investigate adaptation and mitigation, SSPs need to be contrasted along two axes: challenges to mitigation, and challenges to adaptation. This paper proposes a methodology to develop SSPs with a "backward" approach. The methodology is based on (i) an a priori identification of potential drivers of mitigation and adaptation challenges; (ii) a modelling exercise to transform these drivers into a large set of scenarios; (iii) an a posteriori selection of a few SSPs among these scenarios, such that they cover the uncertainty space in terms of challenges to adaptation and mitigation. This methodology is applied to the selection of a few SSPs, but it could also be applied to any specific decisions faced by decision-makers. From a large database of runs built by many models, the methodology would allow selecting the most relevant scenarios for a specific decision, i.e. scenarios that best predict when the analyzed choice performs poorly or well.

Keywords: Socio-Economic Scenarios, Climate Policy, Mitigation, Adaptation, Shared Socio-Economic Pathways, Scenario Elicitation Methodology

JEL Classification: Q42, Q48, D72, O38

Address for correspondence:

Julie Rozenberg

CIRED

45 bis avenue de la Belle Gabrielle

F-94736 Nogent-sur-Marne

E-mail: rozenberg@centre-cired.fr 


\title{
Building SSPs for climate policy analysis: a scenario elicitation methodology to map the space of possible future challenges to mitigation and adaptation
}

\author{
Julie Rozenberg, ${ }^{1,2}$ Céline Guivarch, ${ }^{2}$ Robert Lempert, ${ }^{3}$ and Stéphane Hallegatte ${ }^{4}$
}

\begin{abstract}
The scientific community is now developing a new set of scenarios, referred to as Shared Socioeconomic Pathways (SSPs) to replace the SRES scenarios. To be used to investigate adaptation and mitigation, SSPs need to be contrasted along two axes: challenges to mitigation, and challenges to adaptation. This paper proposes a methodology to develop SSPs with a "backward" approach. The methodology is based on (i) an a priori identification of potential drivers of mitigation and adaptation challenges; (ii) a modelling exercise to transform these drivers into a large set of scenarios; (iii) an $a$ posteriori selection of a few SSPs among these scenarios, such that they cover the uncertainty space in terms of challenges to adaptation and mitigation. This methodology is applied to the selection of a few SSPs, but it could also be applied to any specific decisions faced by decision-makers. From a large database of runs built by many models, the methodology would allow selecting the most relevant scenarios for a specific decision, i.e. scenarios that best predict when the analyzed choice performs poorly or well.
\end{abstract}

\section{A new generation of scenarios}

Most published analyses of climate change mitigation policy, and many investigating climate change impacts and adaptations, are based on long-term socioeconomic scenarios. These scenarios represent "possible and consistent futures" - with or without climate change - on which different policies can be assessed. Up to now, most analyses have used the Special Report on Emissions Scenarios (SRES, see IPCC, 2000). These scenarios describe possible world evolutions in demographic, social, economic, and technological terms, up to 2100.They assume that there are no climate change impacts and no mitigation policies. They have been used as "baselines" to assess the performance of adaptation and mitigation policies and to investigate residual impacts from climate change. For instance, the costs and benefits of climate mitigation policies can be estimated by comparing the change in global mean temperature in a SRES scenario and in the same scenario in which specific climate policies are implemented (see a review in IPCC, 2007). Also, the potential impacts of climate change can be assessed by comparing a SRES scenario with the same scenario in which climate impacts are included (e.g., Arnell, 2004). Since future socioeconomic and environmental changes are highly uncertain, policies need to be tested against a variety of scenarios that cover a large range of possible futures (Lempert 2012; Hallegatte, 2009). It would indeed be dangerous to implement a climate policy that performs well in one given scenario but completely fails in another, for instance if the population is larger or technological change slower than expected.

\footnotetext{
${ }^{1}$ Corresponding author.

${ }^{2}$ CIRED, 45 bis avenue de la Belle Gabrielle, F-94736 Nogent-sur-Marne.

${ }^{3}$ RAND Corporation, Santa Monica Office.

${ }^{4}$ World Bank and Météo France.
} 
The scientific community is now developing a new set of scenarios to replace the SRES (Moss et al., 2010; van Vuuren et al., 2010; Kriegler et al., 2010; Arnell et al.,2011; O'Neill et al., 2012).The new process will build climate and socioeconomic scenarios in parallel, starting from a set of four future paths for anthropogenic impact on the climate system, measured using "radiative forcings." paths are known as representative concentration pathways (RCPs). Climate modelers are currently assessing the climate response to these RCPs. At the same time, Integrated Assessment Model (IAM) modelers will build socioeconomic scenarios, called Shared Socioeconomic Pathways (SSPs), consistent with the RCPs.

As with the earlier SRES scenarios, the new SSPs will describe different socioeconomic characteristics, different vulnerabilities, and different GHG emissions. To assist with the exploration of both adaptation and mitigation questions with the same scenarios, Arnell et al. (2011) propose to develop SSPs that are contrasted along two axes: socio-economic challenges to adaptation and socioeconomic challenges to mitigation (see Figure 1).

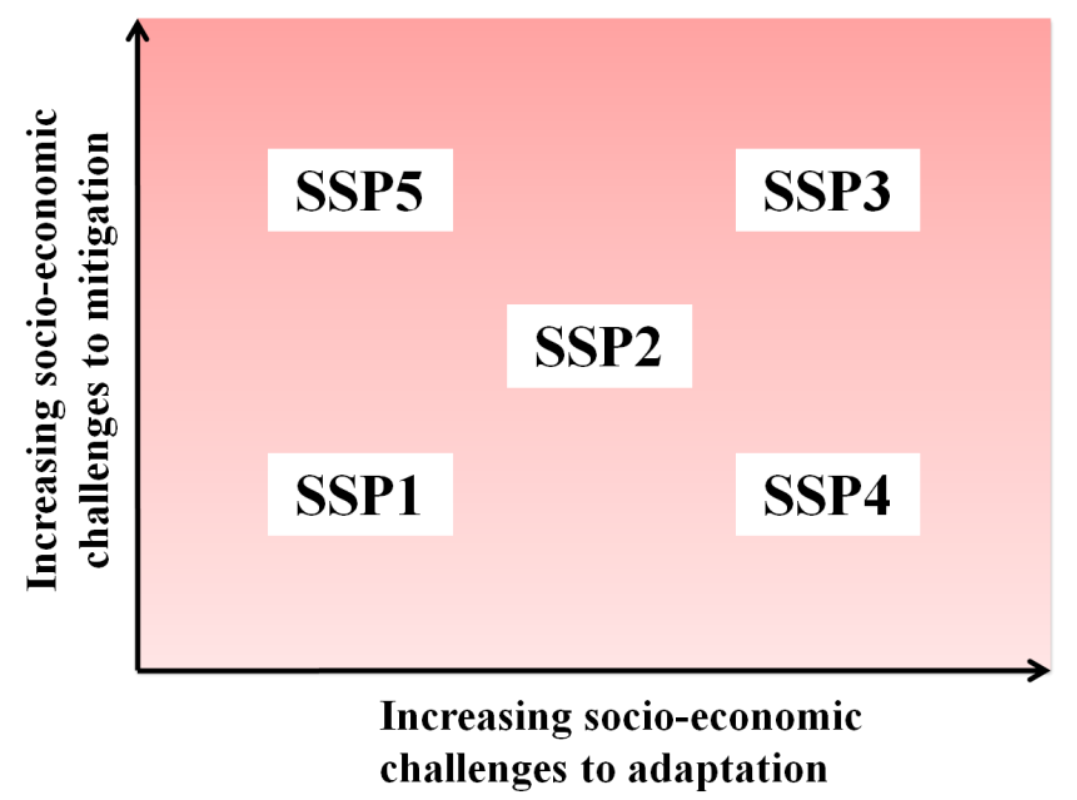

Figure 1: SSPs covering the space of possible futures in terms of challenges to mitigation and challenges to adaptation.

Using traditional scenario methods, groups of experts would choose the SSPs working collaboratively to choose a common set of qualitative storylines, informed by the expert's intuition regarding the most important driving forces leading to different vulnerabilities to climate change and different abilities to mitigate (see O'Neill, 2012 for an illustration with the SSP process). Analysts would then use computer simulation models to develop quantitative projections based on these storylines.

But this process may fail to yield storylines that focus on the most important driving forces for each SSP, and avoid focusing on the less important drivers. For some driving forces, the direction of the influence can be ambiguous a priori. For instance, it is likely that climate change vulnerabilities in a very urban world are different from those in a very rural world; but it is difficult to guess whether one

\footnotetext{
${ }^{5}$ The radiative forcing is the change in net radiative flux at the top of troposphere (i.e., at the tropopause) that results from a change in atmospheric composition (including greenhouse gas [GHG] concentrations); this change takes into account all GHG and is calculated after the stratosphere reaches its equilibrium.
} 
is more or less vulnerable than the other. There is an obvious difference in the nature of vulnerability but not in the intensity of the vulnerability. Moreover, some mechanisms (feedbacks, rebound effects, etc.) might appear negligible a priori but reveal themselves to be crucial in a more careful analysis. This is why an a priori selection of the likely drivers of the capacity to mitigate and adapt appears insufficient to us.

Here, we suggest developing SSPs using a "backward" approach. We start with a large set of model runs that span a wide range of challenges to adaptation and mitigation. We define SSPs in terms of different threshold values for these challenges. We then determine which sets of drivers best determine those SSPs. In consequence, our methodology is based on (i) an identification of potential drivers of challenges to mitigation and adaptation, (ii) a modeling exercise to explore the uncertainty space and select scenarios, and (iii) an a posteriori confirmation of which drivers matter and of the sign of their influence on adaptation and mitigation challenges.

To build a database of many cases, we first identify potential drivers of future challenges to adaptation and mitigation, following, for instance, Hallegatte et al. (2011). Then, we translate some of our potential drivers of these challenges into different model parameters (e.g., the amount of oil resources ultimately recoverable). Others drivers cannot be accommodated in the model and are considered part of a quantitative (or qualitative) narrative, accompanying model parameters and results (e.g. quality of governance). Combining the different states of these drivers (e.g., the amount of oil is low, medium, or large; governance is efficient or not), we build a database of model runs (see Rozenberg et al., 2010 and Section 4 below). We obtain several hundreds of scenarios ${ }^{6}$ by combining these runs with the narrative components that cannot be included in the model.

Once we have constructed the database, we distinguish the scenarios using criteria measuring future challenges to adaptation (e.g., the share of people living below the poverty line) and future challenges to mitigation (e.g., baseline $\mathrm{CO}_{2}$ emissions). We can then choose a few scenarios according to their contrasting results in terms of these criteria. From this selection, we can identify (in a backward way) a set of drivers and model inputs that correspond to these scenarios and can be labeled SSPs.

We identify these drivers using an analytic "scenario discovery" method (Bryant and Lempert, 2010; Groves and Lempert, 2007), which applies statistical algorithms to databases on model results to find those combinations of input parameters most important towards generating model outputs with significant common characteristics. For example, one such scenario discovery analysis focused on mitigation strategies, evaluating the costs and benefits of a Renewable Energy Portfolio standard in the U.S. It found that the availability of low-cost biomass feedstock and low-cost sites for wind energy were the most important drivers for whether or not the policy produced high cost outcomes (Toman et al., 2008). Another analysis focused on adaptation options, evaluating the impact of climate change on the investment plans of a particular California water agency. It found that the most important scenarios to consider included both the severity of climate change and the agency's ability to implement specific components of its investment plan (Lempert and Groves, 2010).

In this study, the scenario discovery algorithms identify the common characteristics (e.g., the demographic changes, the extent of globalization) that best predict the scenarios where the challenges to adaptation or mitigation are high or low. They thus help us select a few SSPs that are contrasted along these criteria.

\footnotetext{
${ }^{6}$ Note that there is no consensus on the terminology used in scenario analysis. Here, we label each of our model runs a "scenario," while the Robust Decision-Making tradition (e.g., Lempert and Groves, 2010) labels them "cases" (and in this case a "scenario" is a "case" that is selected for the analysis of a given decision).
} 
In the case of SSPs, the selected scenarios have to be sufficiently general, since they need to be applicable to a large set of research questions and decisions (e.g., designing a mitigation policy in a city; deciding on an adaptation strategy in water management) and not to a unique decision. But in theory, this "scenario elicitation" methodology can be used to build different sets of scenarios, each decision maker choosing the drivers relevant to a particular policy issue and selecting his or her own scenarios from this common framework.

To summarize, we propose the following approach for developing SSPs:

(i) We first identify a priori the main driving forces of the world future challenges to mitigation and adaptation to climate change, based on existing literature (Section 3).

(ii) We then translate these driving forces into model parameters for a global energy-economic model, and we combine these parameters to build a large number of model runs. We also combine model outputs with "narrative" information to create a large set of scenarios (Section 4). ${ }^{7}$

(iii) We analyze the resulting database using indicators measuring future challenges to mitigation and adaptation to climate change, and we identify a posteriori the main driving forces of these future challenges. Then we select five contrasting combinations of drivers to cover the range of possible challenges to adaptation and mitigation. We propose these five driver combinations as SSPs (Section 5).

The last section discusses how this could define a new approach to the use of scenarios by the climate community. Noting that the most relevant scenarios are often crafted explicitly for specific communities facing specific climate-related decisions (European Environment Agency, 2009; Parson et al., 2006), this new concept envisions providing data and tools that would allow each user to construct his or her own scenarios as needed, while ensuring broad consistency among users with the underlying base of scientific knowledge.

\section{The a priori drivers of challenges to adaptation and mitigation}

Hallegatte et al. (2011) propose three dimensions to explore climate change vulnerability and adaptation challenges, and it appears that these dimensions are also relevant for mitigation challenges. To map the space of possible futures and cover plausible challenges to mitigatation, however, it is necessary to add a fourth one. The four resulting dimensions- globalization, equity, environmental stress, and carbon supply -- are presented in this section.

\subsection{Globalization: a "converging" world vs. a "fragmented" world}

In a converging world, the economic structure of developing countries converges rapidly toward the structure of industrialized countries. For instance, the share of agriculture in their economies decreases in terms of gross domestic product (GDP) and exports. Also, available technologies are similar in industrialized and developing countries; and urbanization rates converge around rich-country

\footnotetext{
${ }^{7}$ The scenario discovery literature generally refers to the entries in the database of model results as cases. Here we use the term scenarios because we have added to the database entries information associated with narratives in addition to the results of model runs.
} 
standards. Developing countries undergo a demographic transition so that population age structure converges and global population growth rates decrease. In a more fragmented world, conversely, developing-country economies catch up more slowly, and for an extended period of time they remain based on agriculture, raw-material extraction, and tourism. These countries remain largely rural. In such a world, developing countries depend more on rich countries for high-technology goods and can balance their imports only thanks to low-value-added goods and services. Population remains young in developing countries, with high fertility and mortality rates, and global population growth rates are higher than in a homogenous world.

This dimension is mainly about changes in economic structures and not trade and openness, even though a converging world has more international trade than a more fragmented one. Indeed, in a homogenous world, industrial and commercial policies seek export-led growth, whereas a fragmented world induces a more inward-oriented growth. In such a world, globalization of financial markets is limited, whereas in a homogenous world, capital markets are integrated.

This dimension is important for IAV (Impacts, Adaptation, and Vulnerability) analysis for two main reasons. First, agriculture in developing countries is likely one of the sectors most negatively affected by climate change (Lobell et al., 2008). In a more homogenous world, these countries would be less vulnerable because agriculture becomes less important in their economy. They would also be at reduced risk of food insecurity because of better access to world food markets, thanks to alternative non agricultural exports (Chen and Kates, 1994). Second, the future of urbanization matters because urban and rural areas have different main vulnerabilities (e.g., floods in urban areas vs. droughts in rural areas). Population matters because it has important impacts on food security, flood risks, or housing.

This dimension is relevant for MP (Mitigation Policies) analysis because the economic structure of developing countries will determine their energy consumption and production. In a fragmented world, developing countries remain mainly rural and based on agriculture, so their future patterns of energy consumption are similar to those today, i.e., much lower than in developed countries. In a converging world, developing countries' energy consumption will depend on the other dimensions, for instance, the type of technologies available and the magnitude of urban sprawl. Population growth rates are important for MP analysis, because higher population growth rates imply higher energy consumption. Even though it is not very well understood yet, population aging is important as wellit might be accompanied by a decline in the number of people per household (a process already observed in industrialized countries). As small households consume more energy per person than large households (Ironmonger et al., 1995), $\mathrm{CO}_{2}$ emissions might increase with increased aging (MacKellaret al., 1995).

\subsection{Equity: inclusive development vs. "growth and poverty" development}

In an inclusive world, the poorest communities have a voice in political choices, national governance takes poverty reduction into account as an important policy goal, and policies successfully reduce the share of people in extreme poverty. Social protection is reinforced so that almost everybody gets access to basic services, such as health care, education, energy and transport, drinking water and sanitation, financial services, secured land tenure, and risk management practices.

In a more "poverty and development" oriented world, a fraction of poor-country population is excluded from these services. 
This dimension is partly independent of the previous one because extreme poverty may either disappear or increase in countries, regardless of their aggregate economic growth.

This dimension can also include differences in terms of governance efficiency. In particular, in an inclusive world, environmental policies are likely to be more efficient than in a "poverty and growth" world. Conversely, a non inclusive world can include a lack of government regulation that often implies the existence of a huge informal sector (Gerxhani, 2004). Indeed, in such a world, informal market labor is likely to be widely developed (undeclared labor, lack of social benefits, subminimum wages, poor working conditions, etc.) (Palmer, 2008).

It is important for IAV analysis to take into account this dimension because poor communities are considered the most vulnerable to climate change (Smit and Wandel, 2006). They are more exposed to environmental conditions (e.g., their access to natural resources, such as water, is not mediated by infrastructure). They also have to cope with multiple stressors (O'Brien et al., 2004) and have less capacity to adapt due to lower financial capacity, education and health, institutional capacity, or political weight, for instance (Yohe and Tol, 2001).

This dimension also has consequences for MP analysis because today, 20\% of the global population lack access to electricity and $40 \%$ rely on traditional use of biomass for cooking (IEA, 2010). The burning of biomass in inefficient stoves emits black carbon, which plays a large role in global and regional warming (Luoma, 2010). In a "strong governance world," households can more easily climb the "energy ladder" (Reddy, 2000; Reddy and Balachandra, 2006). An "inclusive development" world implies universal electricity access and an expansion of household access to modern fuels. This would increase global energy consumption - and global GHG emissions - more than in a "poverty and development" world, even though improved stoves and greater conversion efficiency would reduce its black carbon content (IEA, 2010).

\subsection{Environmental stress: an "environment-oriented" world vs. an "environmentally- stressed" world}

In an environment-oriented world, policies, technologies, management practices, and lifestyles lead to an efficient use of natural resources and reduce environmental stresses. There is a differentiation in consumption behaviors, each region yearning - or being enforced - to follow a more energy-sober development style.

In an environmentally stressed world, water use is inefficient and energy and mobility demands are growing. Soil depletion and degradation are accelerated and reduce agricultural productivity and increase natural risks (e.g., floods). Biodiversity losses are large. In this world, the use of natural resource is already creating environmental stresses, even without climate change, and climate change impacts affect already vulnerable environments.

This dimension is partly independent of the previous ones, since economic development and poverty reduction may be accomplished-temporarily - with or without efficient use of natural resources.

Environmental stress matters for IAV analysis, because ecosystems' ability to cope with climate change depends on the other stresses with which they have to cope (Noble et al., 2005) and additional resource scarcity from climate change can have different consequences depending on how they are 
managed. For instance, reduced rainfall has larger economic consequences if existing resources are already stretched by inappropriate agriculture production and if groundwater is not usable because of pollution or salinization (Arnell, 2004).

This dimension is important for MP analysis, because mobility preferences and spatial organization determine the energy content of economic growth through the populations' need for energy services. Accordingly, an "environment oriented" world has a larger capacity to mitigate climate change than an "environmentally-stressed" world.

\subsection{Carbon dependence: a "high carbon dependence" world vs. a "low carbon dependence" world}

To analyze mitigation, it is important to consider other drivers. In particular, the dependency to fossil fuel will play a critical role, justifying the introduction of a fourth axis in our framework.

In a "low-carbon dependence" world, the availability of fossil energy is low. World oil resources are scarce, with oil production reaching its maximum level before 2020, and gas and coal are expensive to extract. The potential for new technologies is high, and it is easy to orient technical change toward mitigation. Low-carbon technologies, such as electric cars, biofuels, CCS (Carbon Capture and Sequestration), and renewable energy sources are easy to develop, because of a low inertia in the renewal of equipments and fast technical progress.

In a "high-carbon dependence" world, fossil fuels are largely available and fossil energy prices thus remain low for a few decades. The pace and direction of technical change favors carbon-intensive technologies and carbon alternative liquid fuels (e.g., Coal-To-Liquids).

This dimension is partly independent from the previous one because it is driven by geological parameters and some technical parameters independent from the agents' choices (the pace and direction of technical change is partly exogenous and partly endogenous, since it depends on learningby-doing mechanisms and investments in $R \& D$ ).

Carbon supply matters for IAV analysis because carbon dependence will determine the potential for developing adaptation-friendly technologies (e.g., use of desalinization and air conditioning).

It is important for MP analysis because, everything else being equal, mitigation policies will be cheaper if fossil energy prices are high and low-carbon technologies are easy to develop. In a world locked into a carbon-intensive pathway because fossil energy is cheap, mitigation potential is very thin. Indeed, economy sectors are characterized by significant inertia in installed capital, infrastructure, and behaviors that cannot be changed overnight. In some sectors, productive capacities and infrastructures have lifetimes of several decades (IEA, 2000; Worrell and Biermans, 2005; Davis et al, 2010; Guivarch and Hallegatte, 2011). For instance, most industrial installations have lifetimes spanning more than 30 years, whereas urban infrastructure, transport infrastructure, and some buildings have lifetimes lasting over a century. It is likely that urban forms imply an even larger inertia than that suggested by physical capital lifetime (Gusdorf and Hallegatte, 2007; Gusdorf et al., 2008). This inertia constrains the pace of possible decarbonisation of the sectors, and a lock-in of the transportation and residential sectors in carbon-intensive pathways can have very important consequences on mitigation costs. 
The resulting four dimensions are shown in Figure 2, giving an idea of which parameters can be included in each dimension. The figure suggests that some of these parameters can be included in different dimensions (e.g., urbanization can be included in the environmental/lifestyle dimension or in the convergence dimension), showing that there will always be some flexibility and subjectivity in how our approach is applied.

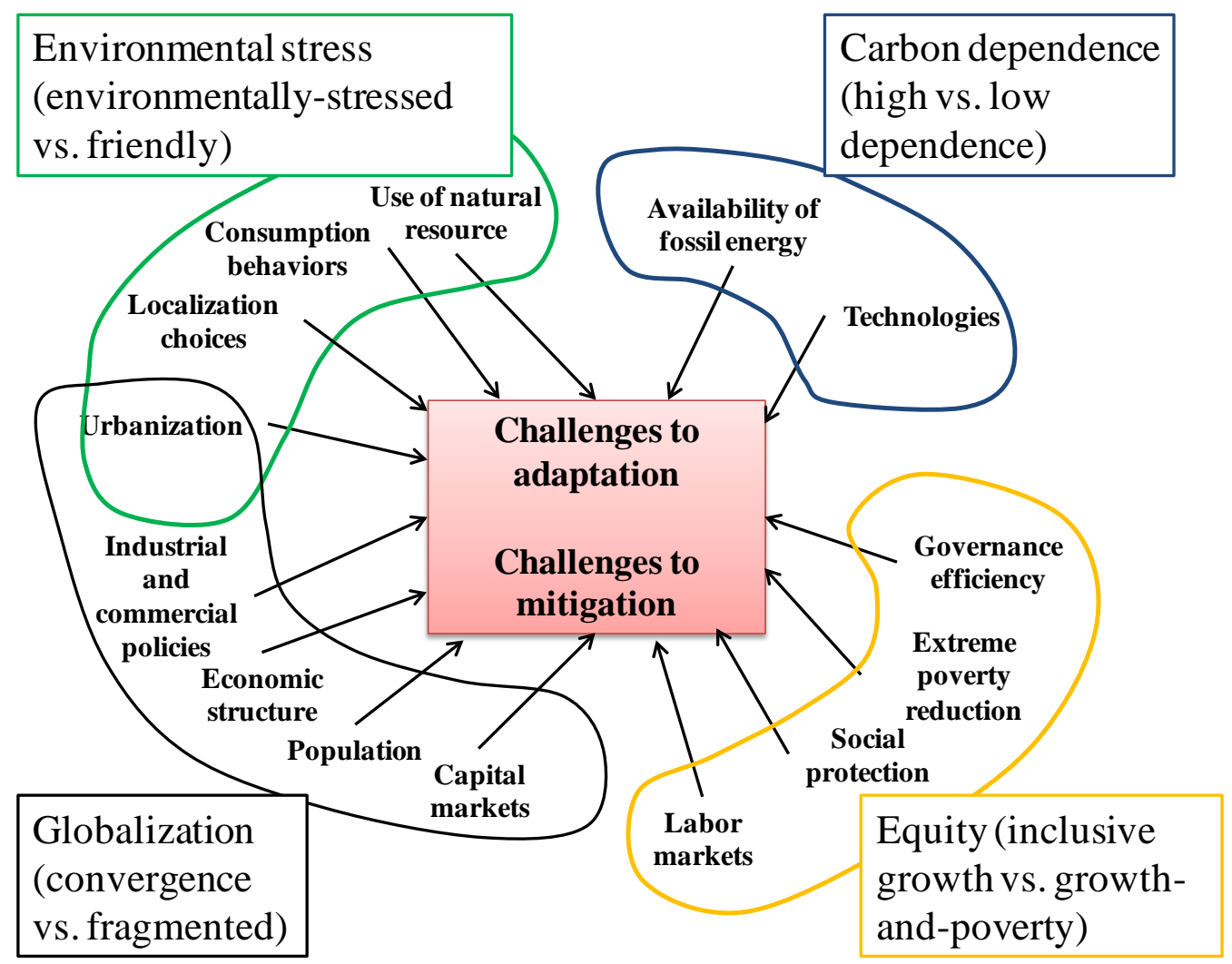

Figure 2: Identified drivers of the challenges to mitigation and adaptation, in the four main dimensions.

\section{How to build scenarios}

There are good reasons to think that these factors will be the major drivers of challenges to adaptation and to mitigation, but this is only an informed guess. Complex mechanisms, interactions, and feedbacks can act on these drivers, and a more sophisticated analysis is possible. To test whether these drivers are well chosen, we translated some of them into model parameters.

To do so, we used the IMACLIM-R model (see the box below), which projects the long-term evolution of the world economy and allows us to explore the uncertainty that arises from unknown exogenous trends (e.g., future population) and parameter values that are debated. 


\section{Description of the IMACLIM-R model.}

IMACLIM-R is a hybrid simulation model of the world economy (Rozenberg et al., 2010; Waisman et al, 2012) which represents in a consistent framework the macro-economic and technological world evolutions.

The growth engine is composed of exogenous demographic trends and of technical progress that increases labor productivity, as in Solow's neoclassical model of economic growth (Solow, 1956). The two sets of assumptions on demography and labor productivity only prescribe natural growth. Actual economic growth then results endogenously from the interaction of these driving forces with short-term constraints: (i) available capital flows for investments and (ii) under-utilization of production factors (labor and capital) due to the possible inadequacy between flexible relative prices (including wages) and inert capital vintages characteristics. Importantly, the model is not based on perfect expectations, but on adaptive expectations reacting on current price signals and past trends. IMACLIM-R, therefore, represents a second-best economy, i.e an economy in which factors utilization may not be optimal. For instance, actual economic growth can thus be constrained by resource availability if resource scarcity was not well anticipated.

Dynamic sub-modules in the model represent the evolution of households' equipment and productive capacities technical characteristics, including technology explicit descriptions of the main elements of the energy system (power generation, vehicles...) and endogenous technical change mechanisms (learning-by-doing, induced energy efficiency).

For a given model, not all drivers can be translated into input parameters. Indeed, some of the drivers are direct inputs of the IMACLIM-R model (e.g., population), some are the result of upstream hypotheses (e.g., the availability of fossil energy is the result of hypotheses on oil resources and inertia in the development of production capacities), and some are model outputs (e.g., economic structure).

For this exercise, we selected the following drivers to be translated into input parameters of the IMACLIM-R model and consider several alternative values for these parameters to reflect uncertainty about future conditions:

\section{Dimension1: Globalization}

Population. We use the three UN scenarios (low, median, and high).

Economic structure. Even though this driver is an output of the IMACLIM-R model, we influence it by introducing three assumptions on the speed of labor productivity convergence (see A1 in Annex 1).

Capital markets. The IMACLIM-R model treats capital balances as exogenous, so we consider two assumptions about global financial imbalances reduction: In the first assumption financial imbalances are phased out exponentially in two decades, whereas in the second assumption they remain constant for the whole simulation period.

\section{Dimension2: Environmental stress}


Energy sobriety. We make two assumptions (i.e. two groups of hypotheses affecting many different variables) regarding energy sobriety:

- Development patterns: We introduce two assumptions on the evolution of households' preferences in transportation and housing (evolution of the number of cars per capita, maximum dwelling surface per capita in developing countries) as well as on the saturation level of households' industrial goods consumption (see A2 in Annex 1).

- Production choices: We introduce two alternatives on the freight content of economic growth through alternative evolutions of the input-output coefficient representing the transportation requirement per unit of good produced (see A2 in Annex 1).

- Induced energy efficiency: Even though energy efficiency is driven by energy prices, we introduce two alternatives for the parameters describing its maximum annual improvement in the leading country and the catch-up speed of the others (see A2 in Annex 1).

\section{Dimension3: Carbon supply}

Availability of fossil energy. We introduce two assumptions about oil resources (parameters include the amount of ultimately recoverable resources, inertia in the deployment of non conventional oil, the maximum growth rate of Middle-East production capacities), the gas price indexation on the oil price, and the elasticities of coal price growth to demand changes (see A3 in Annex 1). Each of these variables can take two different values depending on the assumption.

Availability of low-carbon technologies. We build two assumptions for parameters describing the market penetration of nuclear energy, renewable resources, carbon capture and storage, and electric vehicles. These parameters include learning rates and maximum market shares throughout the simulation period. (More details are given for each technology in A4 in Annex 1.)

\section{Dimension4: Equity}

Dimension 4 has to be treated differently, because its drivers (inequality within countries) cannot be included in the model in its current form. Since the model is based on a representative consumerworker, distribution aspects cannot be taken into account. Considering the importance of this driver, it cannot be disregarded, and we introduce it in a "quantitative narrative," i.e., in numerical information that accompanies model results to build a scenario.

In the current case, therefore, we add to the model outputs a qualitative/quantitative narrative information (an "equity" driver). Some of the scenarios are built assuming a global reduction of within-country inequality (an "inclusive growth" set of scenarios), in which the share of income of the $20 \%$ poorest in countries increases by $33 \%$ by 2090 (e.g., in a country where the $20 \%$ poorest receive an income corresponding to $6 \%$ of total GDP in 2010, this share increases to $8 \%$ in 2090). Others are built assuming a global increase in within-country inequality (a "growth and poverty" world), with a share of income of the $20 \%$ poorest that decreases by $33 \%$ by 2090 . To the model outputs, therefore, we add an additional variable, namely, the income of the $20 \%$ poorest, which is built from model outputs (GDP per capita in less developed countries) and from "narrative" information. 


\section{Resulting scenarios}

The result is a set of 286 scenarios $^{8}$ (see Figures 3 and 4), each being the combination of (1) a set of model parameters describing the drivers, (2) a model run with these parameters, and (3) additional quantitative and qualitative information that cannot be accommodated in the model but are relevant for challenges to adaptation and mitigation (e.g., in our case, inequalities within countries).

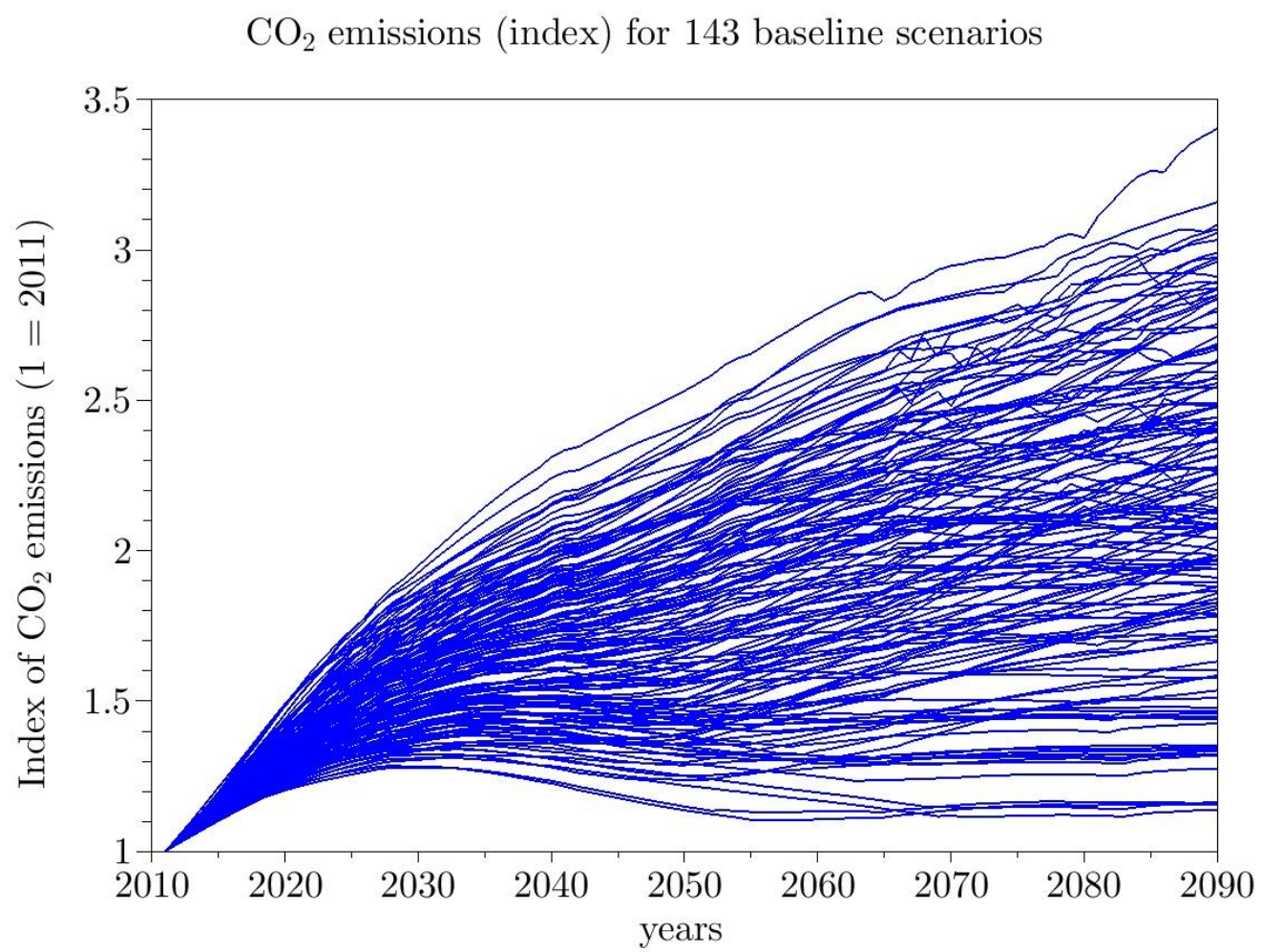

Figure 3: $\mathrm{CO}_{2}$ emissions resulting from 143 model runs with the IMACLIM-R model

\footnotetext{
${ }^{8}$ Combining all assumptions creates 288 model runs, but one baseline did not run until the end of the simulation period. Thus, two scenarios are excluded from the database (derived from this model run and the two hypotheses on equity).
} 
GDP per capita of the $20 \%$ poorest in developing countries in 286 scenarios

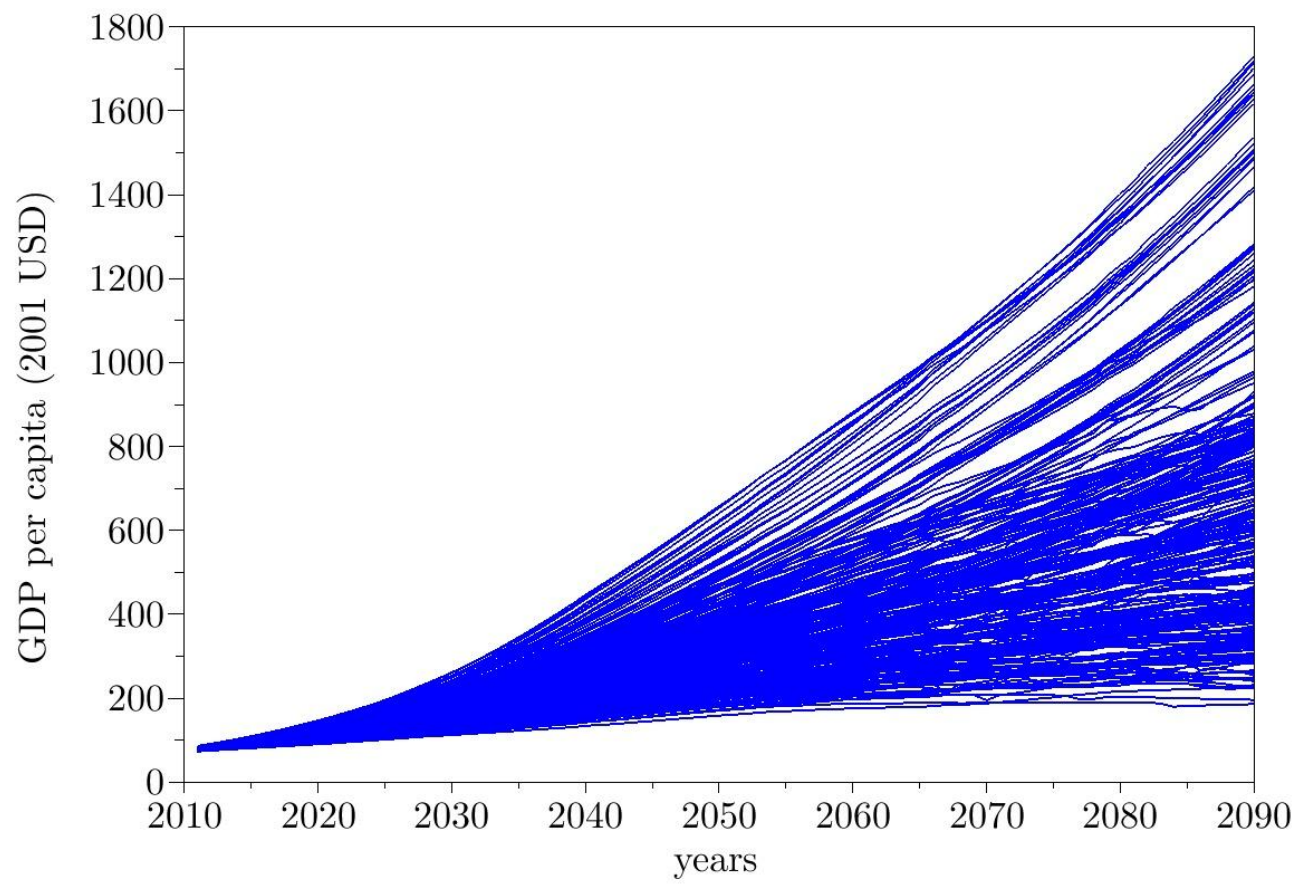

Figure 4: GDP per capita of the $20 \%$ poorest in a selection of developing countries in 286 scenarios resulting from 143 model runs with IMACLIM-R and two hypotheses on the share of income of the $20 \%$ poorest

\section{How to select relevant scenarios}

To select scenarios that cover challenges to mitigation and adaptation, the first step is to define indicators for these challenges. This is a very important (and difficult) endeavor. Much work has been devoted to this task, but there is little agreement on how to proceed. Taking the example of the challenges to adaptation, Füssel (2009) reviews the many indicators that have been proposed and shows that they lead to very different prescriptions and vulnerability hot spots. Also, he shows that vulnerability and adaptive capacity cannot be identified in isolation from political considerations and value and ethical judgments. Our analysis is thus developed and illustrated using very simple indicators, taking into account the fact that more work on this issue needs to be done, and that the methodology needs to be able to accommodate a fairly large set of indicators.

For mitigation, we chose baseline $\mathrm{CO}_{2}$ emissions as an indicator. We are well aware that this measure does not include all components of the challenges to mitigation. For instance, good governance and reduced inequalities are likely to make it easier to implement mitigation policies, regardless of $\mathrm{CO}_{2}$ emissions. But as a first-step analysis, we use this indicator.

For adaptation, no natural indicator is available. Still well aware of the limits, we decided to use the income of the $20 \%$ poorest in a selection of developing countries (African countries, India, South America [except Brazil] and South East Asia). Of course, this is a very partial indicator, and it is well known that challenges to adaptation will depend on many other factors, such as governance and technologies (see the review in Section 2 and in Hallegatte et al., 2011). In the current analysis, we use this very simple indicator only to illustrate our methodology and make a first proposal for SSPs. 


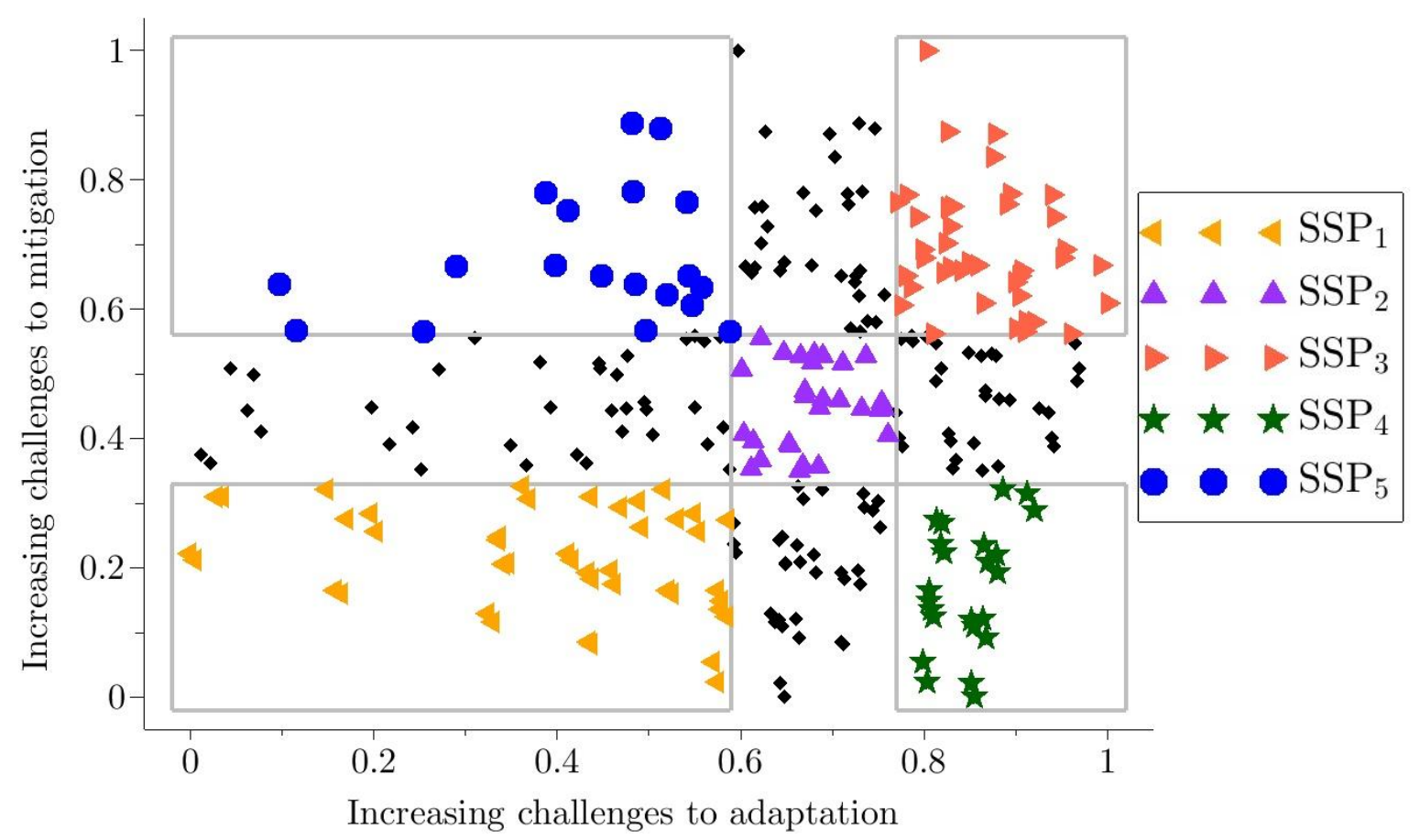

Figure 5: Capacities to adapt and to mitigate that define the five SSP spaces and the results of our 286 model runs arrayed in this space.

We next normalize our two indicators (the sum of global emissions over the 2011-2090 period for challenges to mitigation and the discounted income, over the same period, of the $20 \%$ poorest in developing countries for challenges to adaptation) and map our 286 scenarios over the resulting space. As shown in Figure 5, the scenarios span most combinations of challenges to mitigation and adaptation as defined by these indicators. We then define five regions in this space that correspond to the five SSPs.

In the selection of SSP spaces, we emphasize contrast, i.e., on having scenarios with different challenges to mitigation and adaptation. We do not focus on the "probability," or even the plausibility, of these scenarios. The "plausibility" is supposed to be ensured in the first phase of this analysis, when the determinants have been chosen and transformed into model parameters. We do not want to focus on probabilities because the ability to assess them appears out of reach and because focusing on the most likely scenarios would lead to disregarding low-probability high-impact scenarios, which might be the most relevant in a risk-management approach. Since we think that the analysis of climate policies is an analysis of climate risks more than anything else, the inclusion of low-probability scenarios in SSPs appears essential.

In practice, to select the five SSP boxes, we define numerical thresholds for the challenges to mitigation and adaptation indicators that characterize each SSP. These thresholds are defined such that one-third of the scenarios are below the first threshold and one-third of the scenarios are above the second one (see Figure 5). 
We can now use a "scenario discovery" cluster analysis to identify the main drivers of each scenario group. "Scenario discovery," often used to support robust decision making (Robert Lempert and Kalra, 2011; R J Lempert et al., 2003), provides a computer-assisted method of scenario development that applies statistical or data-mining algorithms to databases of simulation model results to characterize the combinations of uncertain inputs parameter values most predictive of specified classes of results. Importantly, scenario discovery also suggests which uncertain input parameters have less influence.

We apply a modified version of the PRIM (Patient Rule Induction Method) (Friedman and Fisher, 1999) to the 286 scenarios spanning the range of adaptation and mitigation indicators shown in Figure 5. PRIM searches for a combination of a small number of drivers that best explain the conditions that place a case in each of the SSP's.

An SSP is defined by a range of values for the adaptation and mitigation indicators. PRIM seeks set of drivers that maximize the matching between those drivers and the model scenarios that have the indicator values associated with each SSP. For instance, for SSP5, we want to find the drivers such that a scenario with these drivers has a high likelihood of being in the upper-left-hand corner of Fig 5 and such that a scenario is in the upper-left-hand corner has a high likelihood of having these drivers. To measure this match, we use three criteria (see Bryant and Lempert, 2010). Density is the fraction of scenarios consistent with the indicators (e.g. that lie in the SSP5 corner of Fig 5) that are also consistent with the drivers. Coverage is the fraction of all scenarios consistent with the drivers that are also consistent with the indicators. ${ }^{9}$ Interpretability represents that ability of decision makers to understand the information by the combinations of drivers and is measured by having a small number of drivers.

Since these three measures are generally in tension with one another, PRIM provides the user a set of options representing different tradeoffs among density, coverage, and interpretability. Bryant and Lempert (2010) also provide two tests of the statistical significance of each driving force proposed by the PRIM algorithm.

Table 1 shows our results. Each row shows an SSP and the middle eight columns list its potential drivers. A cell filled with black text indicates that a driver plays a significant role in that SSP whereas grey text indicates that the driver plays a partial role. We distinguish the former from the latter using the resampling test described in Bryant and Lempert (2010). This test runs PRIM on multiple subsamples of the original dataset and notes the fraction of subsamples for which each parameter emerges as an important driver of the scenario definition. We consider a driver that scores greater than $50 \%$ in the test as significant and less significant otherwise.

The final column shows the explanatory power of these combinations of drivers, as measured by their coverage and density. For instance, low equity, slow convergence, and high energy sobriety contribute most significantly to SSP4. Ninety percent of the cases in the region of Figure 5 noted as SSP4 meet these conditions (coverage). Eight-five percent of the cases that meet these conditions are SSP4 (density).

\footnotetext{
${ }^{9}$ Coverage is analogous to "sensitivity" or "recall" in the classification and information retrieval literatures. Density is analogous to "precision" or "positive predictive value" in those literatures.
} 
Some drivers, such as equity, contribute strongly to all the SSPs. Indeed, this driver has a direct impact on the challenges to adaptation axis, since it was used to calculate the indicator (see Section 4); this driver splits the income of the $20 \%$ poorest into two groups, with a compression to the right as GDP per capita decreases. In the same way, the "energy sobriety" driver has a strong impact on challenges to mitigation, since it directly influences $\mathrm{CO}_{2}$ emissions in the baseline. It also influences the challenges to adaptation because energy sobriety leads to higher GDP, i.e. to less poverty. ${ }^{10}$

The impact of population on the indicators is ambiguous and not always significant. Indeed, a higher population growth rate implies higher potential economic growth in the model, so that challenges to adaptation might decrease. Moreover, higher economic growth accelerates capital turnover and increases the share of low-carbon technologies, thus decreasing challenges to mitigation. The results show, however, that a high population is inconsistent with SSP1 and that a low population is inconsistent with SSP3.

Other drivers, such as fossil fuel availability and capital markets, contribute to few if any SSPs. The non significant impact of fossil fuel availability is due to two contradictory effects: On the one hand, a constrained oil supply induces substitution toward coal, which emits more $\mathrm{CO}_{2}$ for the same energy service. On the other hand, it also induces higher energy prices, which trigger faster energy efficiency. In the same way, low-carbon technologies contribute to only two SSPs because they tend to slow down energy efficiency through lower energy prices, which lessens their effect on carbon emissions.

\begin{tabular}{|c|c|c|c|c|c|c|c|c|}
\hline & $\begin{array}{c}\text { Equity } \\
\text { (2 options) }\end{array}$ & $\begin{array}{l}\text { Conver- } \\
\text { gence } \\
\text { (3 options) }\end{array}$ & $\begin{array}{c}\text { Energy } \\
\text { sobriety } \\
\text { (2 options) }\end{array}$ & $\begin{array}{l}\text { Availability } \\
\text { of low C } \\
\text { technologies } \\
\text { (2 options) }\end{array}$ & $\begin{array}{l}\text { Availability } \\
\text { of fossil } \\
\text { fuels } \\
\text { (2 options) }\end{array}$ & $\begin{array}{l}\text { Population } \\
\text { (3 options) }\end{array}$ & $\begin{array}{c}\text { Capital } \\
\text { markets } \\
\text { (2 options) }\end{array}$ & $\begin{array}{c}\text { Coverage/ } \\
\text { Density }\end{array}$ \\
\hline $\begin{array}{l}\text { SSP1 } \\
\text { (15\% of } \\
\text { cases) }\end{array}$ & improved & $\begin{array}{l}\text { Fastor } \\
\text { medium }\end{array}$ & high & high & & $\begin{array}{l}\text { Medium } \\
\text { or low }\end{array}$ & & $\begin{array}{l}50 \% / \\
80 \%\end{array}$ \\
\hline $\begin{array}{l}\text { SSP2 } \\
\text { (10\% of } \\
\text { cases) }\end{array}$ & improved & $\begin{array}{l}\text { Medium } \\
\text { or slow }\end{array}$ & low & & & low & & $\begin{array}{l}30 \% / \\
60 \%\end{array}$ \\
\hline $\begin{array}{l}\text { SSP3 } \\
\text { (14\% of } \\
\text { cases) }\end{array}$ & worsen & & low & low & & $\begin{array}{l}\text { High or } \\
\text { medium }\end{array}$ & & $\begin{array}{l}55 \% / \\
90 \%\end{array}$ \\
\hline $\begin{array}{l}\text { SSP4 } \\
\text { (8\% of } \\
\text { cases) }\end{array}$ & worsen & slow & high & & & & & $\begin{array}{l}90 \% / \\
85 \%\end{array}$ \\
\hline $\begin{array}{l}\text { SSP5 } \\
\text { (6\% of } \\
\text { cases) }\end{array}$ & improved & fast & low & & & & $\begin{array}{l}\text { Reduced } \\
\text { imbalances }\end{array}$ & $\begin{array}{l}60 \% / \\
45 \%\end{array}$ \\
\hline
\end{tabular}

Table 1: Combinations of future challenges to adaptation and mitigation in our five SSP spaces as identified by the scenario discovery analysis described in the text. Black/grey

\footnotetext{
${ }^{10}$ The "energy sobriety" driver contains hypotheses on behaviors, localization choices, and the potential for energy efficiency (energy efficiency is endogenous and driven by energy prices). In scenarios with high energy sobriety, energy prices are lower, accelerating GDP growth. This result warns against the use of exogenous GDP scenarios, developed independently from natural resources and energy modeling.
} 
text indicates more/less statistically significant drivers. Coverage and density measure the explanatory power of the drivers for each SSP.

An interesting result of this analysis is the difficulty in finding scenarios corresponding to SSP5 (i.e., scenarios with both high baseline emissions and high GDP growth). Indeed, to include one-third of all scenarios above the second threshold for adaptation challenges, we had to define it at a low value, around 0.4 (see Figure 5). Indeed, as already mentioned, GDP growth is affected by energy consumption and sobriety. If energy consumption is too high (and energy efficiency too low), energy prices are so high than GDP growth is significantly reduced, especially in developing countries. This explains why there are few scenarios with high economic growth and high baseline emissions.

Another conclusion of the analysis is the difficulty to define a unique SSP 2. Indeed, coverage only reaches $30 \%$, which means that $70 \%$ of the scenarios identified as potential SSP2 in Figure 5 corresponds to other drivers than those identified in Table 1. In other terms, there are other sets of drivers that could lead to scenarios with medium challenges to adaptation and mitigation. This quantitative result is consistent with discussions in the Boulder meeting in November 2011 (O'Brian et al., 2012) and the proposition to have several versions of SSP2.

Eventually, this representation allows testing the ex-post relevance of our drivers on our indicators. The hypotheses that we made about financial markets and the future reduction of imbalances are not $a$ posteriori main drivers of the world challenges to adaptation and mitigation, except for SSP5. These results must be moderated, however, because they depend significantly on the choice of indicators and on the delimitation of the SSP spaces. For instance, an analysis focused on China's challenges to mitigation would probably be more influenced by future financial imbalances.

As an illustration, we repeat this analysis in Annex 2 using a different set of indicators. As an indicator of future challenges to mitigation, we calculate the GDP losses from a mitigation policy reducing emissions to stabilize radiative forcing at a given level (we retain a target at $3.7 \mathrm{Wm}^{-2}$ ). For adaptation challenges, we use the share of jobs in agriculture in developing countries.

The results of this second analysis share some similarities with those of the first one (see Table 3 in Annex 2); for instance, convergence is slow for SSP4 and fast for SSP5; energy sobriety is high for SSP1 and low for SSPs 3 and 5. But significant differences can also be noted. For instance, low-carbon technologies matter more than in the first analysis, since they are significant in SSPs 1, 3, 4 and 5. This is due to the mitigation challenges indicator (i.e., the GDP cost of a mitigation policy): The two opposing effects of low-carbon technologies on $\mathrm{CO}_{2}$ emissions (through lower energy efficiency) do not apply on this new indicator because low-carbon technologies help meet the climate objective at a lower cost without slowing down energy efficiency, which is triggered by the carbon tax in all scenarios. In this second analysis, capital markets are significant in three SSPs because they have an impact on the adaptation challenges indicator: a reduction of financial imbalances (as in SSP1 for instance) induces developing countries to invest more locally. This accelerates structural change and reduces the share of jobs in agriculture.

The similarities and differences in these two analyses, with different criteria for challenges to mitigation and adaptation, constitute a first indication of the robust results for SSPs development. To go further, we consider only scenarios that are in the same SSP domain for both sets of indicators. For each SSP domain, only about ten scenarios are stable to a change of indicators, and they have a few drivers in common: 
- SSP1 (11 scenarios): these scenarios are characterized by a high availability of low-carbon technologies, energy-sober behaviors and a reduction in financial imbalances.

- SSP2 (5 scenarios): there is no common characteristic to those scenarios.

- SSP3 (7 scenarios): these scenarios are the exact opposite of the SSP1 scenarios, and are characterized by a low availability of low-carbon technologies, energy-intensive behaviors and maintained financial imbalances.

- SSP4 (11 scenarios): these scenarios are characterized by low equity, low convergence and maintained financial imbalances.

- SSP5 (10 scenarios): these scenarios all have a high convergence, nine of them have a low availability of low carbon technologies and nine of them have reduced financial imbalances.

These results confirm that it is difficult to find a unique set of drivers defining SSP2; this intermediate scenario can be represented by very different futures. They also show that the relevant set of drivers depend on which SSP is considered. Interestingly, SSP1 and SSP3 are defined by the same set of drivers - but with opposite values - that mainly describes the energy system (technologies and energy intensity). Conversely, SSP4 and SSP5 are characterized by assumptions on socio-economic aspects, and particularly equity and economic convergence.

This analysis remains preliminary and the robustness of its results would be increased by the inclusion of additional driver values, additional drivers, alternative selection criteria, and more models. In particular, combining different models with different designs would be key to improve our confidence in the SSP determinants.

\section{Conclusion and further challenges}

A central goal of scenario exercises is to inform the development of robust strategies, that is, strategies that perform better than the alternatives over a wide range of plausible future states of the world. When this process is successful, it can be surprising that uncertain factors do not affect the relative performance of a robust strategy.

Such context dependence of the most important scenarios for decision making presents both an opportunity and a challenge for the choice of socioeconomic scenarios. The opportunity is that it provides a clear definition of the most policy-relevant scenarios - those that most directly inform the tradeoffs among strategies. But it also suggests the need for different sets of scenarios for different decisions.

But as a first step, we propose in this paper an illustration of how this methodology could be applied to define a first set of SSPs, appropriate for a broad range of decisions concerning climate policies, including mitigation and adaptation. We show that this approach allows for the development of five baseline SSPs that have very different challenges to adaptation and mitigation (at least according to the very simple indicators we used in this study).

Most importantly, the development of SSPs will not be a one-shot exercise. Instead, it will be a continuous process of refinement. The methodology that is proposed here could be applied to an increasingly large set of scenarios produced using different methods and models. The methodology would indeed be particularly relevant if a large number of diversified models are used to construct the scenario database in which SSPs are selected. Also, it would be particularly useful to develop a large set of selection criteria, which could be used to select SSPs that are particularly adapted to a specific problem. 
Over the long term, one can imagine a large multimodel scenario database and a diversity of selection criteria that can be used to identify which scenarios are most relevant for a given category of decisions. A web-based tool could then be proposed to allow decision makers to select the few scenarios that they need to consider in their decision making process. Such a tool would benefit from the multiplicity of models available in the literature. It would also avoid the difficult selection of a few marker scenarios, which will inevitably oversimplify the reality and result in the discarding of a lot of useful information.

\section{References}

Arnell N. W. (2004), Climate change and global water resources: SRES emissions and socio-economic scenarios, Global Environmental Change, 14(1), 31-52

Arnel N. W, T. Kram, T. Carter, K. Ebi, J. Edmonds, S. Hallegatte, E. Kriegler, R. Mathur, B. O'Neill, K. Riahi, H. Winkler, D. van Vuuren, T. Zwickel, A framework for a new generation of socioeconomic scenarios for climate change impact, adaptation, vulnerability, and mitigation research.

Bryant, B. P., and R. J. Lempert (2010), Thinking inside the box: A Participatory, computer-assisted approach to scenario discovery, Technological Forecasting and Social Change, 77, 34-49.

Chen, R.S., and R. W. Kates (1994), World food security: prospects and trends, Food Policy, 19(2), 192-208

Davis S. J., K. Caldeira, H. D. Matthews (2010) Future CO2 emissions and climate change from existing energy infrastructure. Science 329:1330-1333

European Environment Agency (EEA) (2009), Looking back on looking forward: a review of evaluative scenario literature Rep. ISSN 1725-2237 European Environmental Agency, Copenhagen.

Friedman, J. H., and N. I. Fisher (1999), Bump Hunting in High-Dimensional Data, Statistics and Computing, 9, 123-143.

Füssel H.-M. (2009), Review and quantitative analysis of indices of climate change exposure, adaptive capacity, sensitivity, and impacts. Background note to the World Development Report 2010, World Bank, Washington, D.C.

Gërxhani, K. (2004), The Informal Sector in Developed and Less Developed Countries: A Literature Survey, Public Choice, 210(3), 276-300, Issn: 0048-5829

Groves, D. G., and R. J. Lempert (2007), A New Analytic Method for Finding Policy-Relevant Scenarios, Global Environmental Change, 17, 73-85.

Guivarch C. and S. Hallegatte, 2011. Existing infrastructure and the $2{ }^{\circ} \mathrm{C}$ target, Climatic Change Letters 109(3), 801-805

Gusdorf, F. and S. Hallegatte, 2007. Compact or Spread-Out Cities: Urban Planning, Taxation, and the Vulnerability to Transportation Shocks, Energy Policy, 35, 4826-4838. 
Gusdorf, F., S. Hallegatte, A. Lahellec, 2008, Time and space matter: how urban transitions create inequality, Global Environment Change 18(4), 708-719.

Hallegatte, S., 2009: Strategies to adapt to an uncertain climate change, Global Environmental Change 19, 240-247.

Hallegatte, S., V. Przyluski, A. Vogt-Schilb (2011), Building world narratives for climate change impact, adaptation and vulnerability analyses. Nature Climate Change, 1(3), p.151-155.

IEA (2000), World Energy Outlook 2000. International Energy Agency, Paris

IEA (2010), World Energy Outlook 2010. International Energy Agency, Paris

Ironmonger, D., C., Aitkane, and B. Erbas (1995), Economies of scale in energy use in adult-only households. Energy Economics, 17(4), 301-310.

IPCC (2000), Special Report on Emissions Scenarios (SRES). N. Nakicenovic and R. Swart (Eds.), Cambridge University Press, UK. pp 570

IPCC (2007). The IPCC 4th Assessment Report, Technical report, Intergovernmental Panel on Climate Change (IPCC)

Kriegler, E. et al. (2010) Socio-economic Scenario Development for Climate Change Analysis, CIRED Working Paper

Lempert, R., and D. G. Groves (2010), Identifying and Evaluating Robust Adaptive Policy Responses to Climate Change for Water Management Agencies in the American West, Technological Forecasting and Social Change, 77, 960-974.

Lempert, R., and N. Kalra (2011), Managing Climate Risks in Developing Countries with Robust Decision MakingRep., World Resources Report, Washington DC.

Lempert, R. J., S. W. Popper, and S. C. Bankes (2003), Shaping the Next One Hundred Years : New Methods for Quantitative, Long-term Policy Analysis, xxi, 187 p. pp., RAND Corporation, Santa Monica, CA.

Lempert, R. J. (2012), Scenarios that Illuminate Vulnerabilities and Robust Responses, In preparation

Lobell, D.B., et al. (2008), Prioritizing Climate Change Adaptation Needs for Food Security in 2030. Science 319, 607

Luoma, J. (2010), «World's Pall of Black Carbon Can Be Eased with New Stoves », Yales environment 360, 8 March, Yale School of Forestry and Environmental Studies, New Haven.

MacKellar, F.L., W. Lutz, C. Prinz, and A. Goujon (1995), Population, households and $\mathrm{CO}_{2}$ emissions. Population and Development Review, 21(4), 849-865.

Moss, R. H. et al. (2010), The next generation of scenarios for climate change research and assessment. Nature 463, 747-756 
Noble et al. (2005), Climate change. In K. Chopra et al., Eds. Ecosystems and Human Well-Being. Policy Responses. Findings of the Responses Working Group. Island Press, Washington, DC, 373400.

O'Brien, K. et al. (2004), Mapping vulnerability to multiple stressors: climate change and globalization in India, Global Environmental Change, 14(4), 303-313.

O’Neill, B.C., Carter, T., Ebi, K.L., Edmonds, J., Hallegatte, S., Kemp-Benedict, E., Kriegler, E., Mearns, L., Moss, R., Riahi, K., van Ruijven, B., van Vuuren, D. (2012). Meeting Report of the Workshop on The Nature and Use of New Socioeconomic Pathways for Climate Change Research, Boulder, CO, November 2-4, 2011. Available at: http://www.isp.ucar.edu/socio-economic-pathways.

Palmer, R. (2008), ILO, Employment Working Paper $\mathrm{N}^{\circ}$ 5: Skills and productivity in the informal economy.

Parson, E. A., V. Burkett, K. Fischer-Vanden, D. Keith, L. Mearns, H. Pitcher, C. Rosenweig, and M. Webster (2006), Global-Change Scenarios: Their Development and Use, Synthesis and Assessment Product 2.1b, public review draft Rep., US Climate Change Science Program.

Reddy, A. K. N. (2000). Energy and social issues.World Energy Assessment, Energy and the challenge of sustainability.Goldemberg, J. Ed. New York, UNDP.

Reddy, B. S. and P. Balachandra (2006). "Dynamics of technology shifts in the household sector -implications for clean development mechanism." Energy Policy 34(16):2586-2599.

Rozenberg J., S. Hallegatte, A. Vogt-Schilb, O. Sassi, C. Guivarch, H. Waisman and J.-C. Hourcade, (2010), Climate policies as a hedge against the uncertainty on future oil supply. Climatic Change 101(3-4): 663-668

Smit, B. and J. Wandel (2006), Adaptation, adaptive capacity and vulnerability, Global Environmental Change, 16(3), 282-292

Solow RM (1956) A contribution to the theory of economic growth. Quarterly Journal of Economics 70:65-94

Toman, M. A., J. Griffin, and R. J. Lempert (2008), Impacts on U.S. energy expenditures and greenhouse-gas emissions of increasing renewable-energy use : technical reportRep. 9780833044976 (pbk. alk. paper), xvii, 54 p. pp, RAND Corp., Santa Monica, CA.

vanVuuren, D. P. et al. (2010), Developing New Scenarios as a Thread for Future Climate Research IPCC Working Paper.

Waisman, H.D., C. Guivarch, F. Grazi, J.-C. Hourcade (2012), The Imaclim-R Model: Infrastructures, Technical Inertia and the Costs of Low Carbon Futures under Imperfect Foresight. Climatic Change (forthcoming) DOI 10.1007/s10584-011-0387-z

Worrell, E. and G. Biermans (2005), Move over! Stock turnover, retrofit and industrial energy efficiency. Energy Policy, 33(7), pp. 949-962. 
Yohe, G. and R.S.J. Tol, (2001).Indicators for social and economic coping capacity - moving toward a working definition of adaptive capacity. Global Environmental Change, 12(1), 25-40 


\section{Annex 1: description of the alternatives}

\section{A1. Natural growth drivers}

The natural growth rate of the economy defines the growth rate that the economy would follow if it produced a composite good at full employment, like in standard neoclassical models developed after Solow (1956). In the IMALCIM-R model, it is given by exogenous assumptions on active population and labor productivity growth. We build three alternatives for population, using demographic data on active population derived from UN scenarios (low, medium and high).

We also define three alternatives on labor productivity growth. Equation A-1 represents labor productivity growth through the decrease of unitary labor input $l$ in each region $j$ and at each time step $t$. In this equation, $\tau_{2}$ can be equal to 55,120 or 250 years depending on the assumption on convergence.

$$
l t, j=e^{-\frac{t}{\tau_{1}}} \cdot l t_{0}, j+1-e^{-\frac{t}{\tau_{1}}} \cdot \frac{1}{\tau_{2}} \cdot l t, j-l(t, \text { leader })+l(t, \text { leader })
$$

\section{A2. Energy sobriety}

Historically, the literature on the decoupling between energy and growth has focused on autonomous energy efficiency improvements (implicitly encompassing end-use energy efficiency and structural changes) and on the energy efficiency gap, i.e. the difference between the most energy efficient technologies available and those actually in use.

However important it may be, energy efficiency is not the only driver of energy demand. Indeed, the rate and direction of technical progress and its energy content depend, not only on the transformation of the set of available techniques, but also on the structure of households' demand. This is why IMACLIM-R endogenizes both energy efficiency strict sensu, and the structural change resulting from the interplay between consumption, technology and localization patterns. This enables us to capture the effect of non-energy determinants of energy demand, such as the prices of land and real estate, and political bargaining (set exogenously) over urban infrastructure to be represented. This endogenization of technical change is made for both stationary uses (industry and services, buildings) and nonstationnary uses (freight and passenger transportation).

For energy sobriety, we build three assumptions using parameters which describe (a) energy efficiency, (b) development patterns in transport, housing and industrial goods consumption and (c) localization patterns. All assumptions are summed-up in Table 2.

\section{Energy efficiency}

In each sector, the country with the lowest energy intensity is the leader and its energy efficiency is triggered by energy prices. The other countries catch-up with the leader after a delay. We build two hypotheses using the following parameters (see Table 2): maximum annual improvement in the leader's energy efficiency, other countries' speed of convergence ( $\%$ of the initial gap after 50 years) and asymptotic level of catch-up ( $\%$ of the leader's energy efficiency).

\section{Development patterns}

\section{Transport}

Passenger mobility needs and their modal breakdown across four travel modes (ground-based public transport, air transport, private vehicles and non-motorized modes) result from the maximization of households' utility under the assumption of constant travel time (Zahavi and Talvitie, 1980) and budget constraints. This helps to represent two crucial determinants of the demand for passenger 
transportation, namely the induction of mobility demand by infrastructure and the conventional rebound effect consecutive to energy efficiency gains on vehicles (Greening et al, 2000).

In addition to the availability of transportation infrastructure and energy efficiency, mobility needs are dependent upon agents' localization choices (Grazi et al., 2008). This is captured by differences in regional households' motorization rates, everything else being equal (income, energy prices), with dispersed spatial organizations implying a higher dependence on private transport. In each region, the motorization rates increase with disposable per capita income through variable income-elasticity $\eta_{\text {mot }}$ : (a) low for very poor people whose access to motorized mobility relies on non-motorized and public modes; $(b)$ high for households with a medium per capita income with access to private motorized mobility (c) low again, because of saturation effects, for per capita income level comparable to that of the OECD. We make two hypotheses on this parameter for developing countries, representing the evolution of preferences (see Table 2).

\section{Buildings}

The 'Housing and Buildings' module represents the dynamics of energy consumption as a function of the energy service level per housing square meter (heating, cooling, etc.) and the total housing surface. The former is represented by coefficients encompassing the technical characteristics of the existing stock of end-use equipment and buildings and the increase in demand for energy services: heating, cooking, hot water, lighting, air conditioning, refrigeration and freezing and electrical appliances.

Housing surface per capita has an income elasticity of $\eta_{H}$, and region-specific asymptotes for the floor area per capita, $h_{\max }$. This limit reflects spatial constraints, cultural habits as well as assumptions about future development styles (including the lifestyles in emerging countries vis-à-vis the US, European or Japanese way of life). To account for different development patterns, we make two hypotheses on $h_{\max }$ in developing countries (see Table 2).

\section{Industrial goods}

The industrial and services sectors are represented in an aggregated manner, each of them covering a large variety of economic sub-sectors and products. Technical change then covers not only changes and technical progress in each sub-sector but also the structural effects across sectors. In addition to autonomous energy efficiency gains, the IMACLIM-R model represent the structural drop in energy intensity due to a progressive transition from energy-intensive heavy industries to manufacturing industries, and the choice of new techniques which results in both energy efficiency gains and changes in the energy mix.

The progressive switch from industry to services is controlled by saturation levels of per capita consumption of industrial goods (in physical terms, not necessarily in value terms), via an asymptote at $\kappa_{\text {ind }}$ multiplied by its level in 2001. For developing countries, these saturation levels represent various types of catch-up to the consumption style in developed countries. We thus make two hypotheses on this parameter (see Table 2).

\section{Localisation choices: freight content of economic growth}

In the freight sector, total energy demand is then driven by freight mobility needs, in turn depending on the level of economic activities and their freight content. Even though the share of transportation in total costs is currently low, decoupling freight mobility demand and economic growth is an important determinant of long-term mitigation costs. In the absence of such a decoupling (constant input-output coefficient), and once efficiency potentials in freight transportation have been exhausted, constraining sectoral carbon emissions from freight transportation would amount to constraining economic activity. We thus build two alternative evolutions of the input-output coefficient representing the transportation requirement per unit of good produced (see Table 2).

\begin{tabular}{|l|l|l|l|}
\hline & & Assumption 1 & Assumption 2 \\
\hline Energy efficiency & $\begin{array}{l}\text { maximum annual } \\
\text { improvement in the }\end{array}$ & $1.5 \%$ & $0.7 \%$ \\
\hline
\end{tabular}




\begin{tabular}{|c|c|c|c|}
\hline & \multirow{2}{*}{$\begin{array}{l}\text { leader's } \\
\text { efficiency }\end{array}$} & \multirow[b]{2}{*}{$10 \%$} & \multirow[b]{2}{*}{$50 \%$} \\
\hline & & & \\
\hline & $\begin{array}{lrr}\text { asymptotic } & \text { level } & \text { of } \\
\text { catch-up }(\% & \text { of } & \text { the } \\
\text { leader's } & & \text { energy } \\
\text { efficiency }) & & \end{array}$ & $95 \%$ & $60 \%$ \\
\hline Transport & $\begin{array}{l}\text { Motorization rate growth } \\
\text { with GDP per capita } \\
\left(\eta_{\text {mot }}\right)\end{array}$ & $\begin{array}{l}\text { Values from IEA data } \\
\text { (Fulton and Eads, 2004) }\end{array}$ & $\begin{array}{l}50 \% \text { increase w.r.t As- } \\
\text { sumption } 1 \text { value }\end{array}$ \\
\hline \multirow[t]{3}{*}{ Buildings } & $\begin{array}{ll}\text { Income } & \text { elasticity of } \\
\text { buildings } & \text { stock growth } \\
\left(\eta_{H}\right) & \end{array}$ & 0.7 & 1 \\
\hline & $\begin{array}{l}\text { Asymptote to surface per } \\
\text { capita in China and India } \\
\left(h_{\max }\right)\end{array}$ & 40 & 60 \\
\hline & $\begin{array}{l}\text { Start year and fuel price } \\
\text { for a forced decline of oil } \\
\text { consumption in this } \\
\text { sector }\end{array}$ & $2010-1000 \$ /$ tep & $2020-1300 \$ /$ tep \\
\hline Industrial goods & $\begin{array}{lr}\text { households } & \text { industrial } \\
\text { goods } & \text { consumption } \\
\text { saturation } & \text { level } \\
\max ]\left(\kappa_{\text {ind }}\right) & \end{array}$ & [1-2] & {$[1.5-3]$} \\
\hline $\begin{array}{l}\text { Localisation } \\
\text { choices: freight } \\
\text { content r of } \\
\text { economic growth }\end{array}$ & $\begin{array}{l}\text { Input-output coefficient } \\
\text { of transportation } \\
\text { requirement per unit of } \\
\text { good produced }\end{array}$ & $\begin{array}{l}\text { decreases along with } \\
\text { labor productivity } \\
\text { growth in the composite } \\
\text { sector and along with } \\
\text { energy efficiency in the } \\
\text { industry sector }\end{array}$ & Constant in all sectors \\
\hline
\end{tabular}

Table 2: parameters of the two assumptions on energy sobriety

\section{A3. Availability of fossil energy}

\section{Oil supply}

The modeling structure of oil supply in IMACLIM-R embarks three crucial specificities of oil supply:

(a) a small group of suppliers benefits from a market power.

(b) the geological nature of oil reserves imposes a limited adaptability of oil supply.

(c) uncertainties on the technical, geopolitical and economical determinants of oil markets alter agents' expectations. The assumption of perfectly optimizing atomistic agents, which remains a useful analytical benchmark, fails to provide a good proxy for the oil economy.

We distinguish seven categories of conventional and five categories of non-conventional oil resources in each region. Each category $i$ is characterized by the amount of ultimate resources ${ }^{11} Q_{\infty, i}$ and by a threshold selling price above which producers initiate production, $p^{(0)}(i)$. This price is a proxy for production costs and accessibility.

\footnotetext{
${ }^{11}$ Ultimate resource of a given category is the sum of resources extracted before 2001 and recoverable resources.
} 
Each oil category is submitted to geological constraints (inertias in the exploration process and depletion effects), which limit the pace of expansion of their production capacity. In line with Rehrl and Friedrich (2006), who combine analyzes of discovery processes (Uhler, 1976) and of the "mineral economy" (Reynolds, 1999), we impose, at each date $t$, an upper bound $\Delta \operatorname{Cap}_{\max }(t, i)$ on the increase of production capacity for an oil category $i$ :

$$
\frac{\Delta \operatorname{Cap}_{\max }(t, i)}{\operatorname{Cap}(t, i)}=\frac{b_{i} \cdot e^{-b_{i}\left(t-t_{0, i}\right)}-1}{1+e^{-b_{i}\left(t-t_{0, i}\right)}}
$$

The parameter $b_{i}$ (in $t^{-1}$ ) controls the intensity of constraints on production growth: a small (high) $b_{i}$ means a flat (sloping) production profile to represent slow (fast) deployment of production capacities. The parameter $t_{0, i}$ represents the date at which production capacities of the concerned oil category are expected to start their decline due to depletion effects. It is endogenous and varies in time since it depends on the amount of oil remaining in the soil given past exploitation decisions.

The production decisions of non-Middle-East producers are those of 'fatal producers' who do not act strategically on oil markets and invest in new production capacity if an oil category becomes profitable given the selling oil price $p_{\text {oil }}$. They develop production capacities at their maximum rate of increase in eq (A-2) for least-cost categories $\left(p_{\text {oil }}>p^{(0)}(i)\right)$ but stop investments in high-cost categories ( $\left.p_{\text {oil }}<p^{(0)}(i)\right)$. If prices continuously increase, production capacities of a given oil category follow a bell-shape trend, whereas their deployment profile passes through a plateau if prices decrease below the profitability threshold.

Middle-East producers are 'swing producers' who fill the gap between fatal producers' supply and global oil demand. The stagnation and decline of conventional oil in the rest of the world temporarily reinforces their market power and they can control the time profile of oil prices through the utilization rate of production capacities (Kaufmann et al, 2004). They can decide to slow the development of production capacities down (below the maximum increase given by eq (A-2)) in order to adjust the oil price according to their rent-seeking objective.

Total oil production capacity at date $t$ is given by the sum over oil categories with different production costs (captured by different $p^{(0)}(i)$ threshold). This means that projects of various merit orders coexist at a given point in time, consistently with the observed evidence ${ }^{12}$ and theoretical justifications ${ }^{13}$.

For this sector, we build two assumptions using the following parameters: amount of ultimately recoverable resources $\left(Q_{\infty}\right)$, inertia in the deployment of non conventionals (spread of the bell-shaped curve $b$ ), maximum growth rate of Middle-East capacities and OPEC target oil price (see Table 3).

\section{Gas supply}

The evolution of worldwide natural gas production capacities meets demand increase until available reserves enter a depletion process. Distribution of regional production capacities in the 'gas supply' module is made using an exogenous distribution key calibrated on the output of the POLES energy model (LEPII-EPE, 2006), which captures reserve availability and regional production facilities. Gas markets follow oil markets with a 0.68 elasticity of gas to oil price. This behavior is calibrated on the

\footnotetext{
${ }^{12}$ For example, low-cost fields in Saudi Arabia and high-cost non-conventional production in Canada are simultaneously active on oil markets

${ }^{13}$ Kemp and Van Long (1980) have indeed demonstrated that, in a general equilibrium context, the lowest-cost deposits are not necessarily exploited first. Holland (2003) even demonstrates that least-cost-first extraction rule does not hold in partial equilibrium under capacity constraints, like those envisaged for geological reasons here.
} 
World Energy Model (IEA, 2007) and is valid as long as oil prices remain below a threshold $p_{\text {oil/gas }}$. At high price levels reflecting tensions due to depletion of reserves, gas prices are driven by production costs and the increased margin for the possessors of the remaining reserves. We make two hypotheses on $p_{\text {oil/gas }}$ (see Table 3 ).

\section{Coal markets}

Unlike oil and gas markets, cumulated coal production has a weak influence on coal prices because of large world resources. Coal prices then depend on current production through elasticity coefficients. To represent the asymmetry in coal price response to production variations, we consider two different values of this elasticity, $\eta^{+}$coal and $\eta_{\text {coal }}$, the former (latter) corresponding to a price reaction to a production increase (decrease). Tight coal markets exhibit a high value of $\eta^{+}$coal (i.e the coal price strongly increases if production rises) and low value of $\eta_{\text {coal }}^{-}$(the price decreases only slightly if production drops). For this sector, we make two hypotheses for $\eta^{+}$coal and $\eta_{\text {coal }}^{-}$(see Table 3 ).

\begin{tabular}{|l|l|l|}
\hline & Assumption 1 & Assumption 2 \\
\hline $\begin{array}{l}\text { Amount of ultimately recoverable resources (see } \\
Q_{\infty} \text { in equation A-1) }\end{array}$ & $3.6 \mathrm{~Tb}$ & $3.1 \mathrm{~Tb}$ \\
\hline $\begin{array}{l}\text { Inertia in the deployment of non conventionals } \\
\text { (spread of the bell-shaped curve: see } b \text { in } \\
\text { Equation A-1) }\end{array}$ & No inertia $(\mathrm{b}=0.061)$ & No inertia $(\mathrm{b}=0.041)$ \\
\hline Maximum growth rate of Middle-East capacities & $1.1 \mathrm{Mbd} / \mathrm{yr}$ & $0.7 \mathrm{Mbd} / \mathrm{yr}$ \\
\hline OPEC target oil price & $80 \$ / \mathrm{bl}$ & $120 \$ / \mathrm{bl}$ \\
\hline Indexation of gas price on oil price & $p_{\text {oil/gas }}=80 \$ / \mathrm{bl}$ & No threshold \\
\hline $\begin{array}{l}\text { Price growth elasticity to production decrease } \\
\left(\eta_{\text {coal }}^{-}\right)\end{array}$ & 1.5 & 1 \\
\hline $\begin{array}{l}\text { Price growth elasticity to production increase } \\
\left(\eta^{+} \text {coal }\right)\end{array}$ & 1 & 4 \\
\hline
\end{tabular}

Table 3: parameter choices for the two assumptions on fossil fuels.

\section{A4. Availability of low-carbon technologies}

In the IMACLIM-R model technologies penetrate the markets according to their profitability, but are constrained by a maximum market share which follows a "S-shaped curve"(Grübler et al, 1999) and of which parameters are described in Table 4.

\begin{tabular}{|c|c|c|c|c|c|c|c|c|}
\hline & \multicolumn{2}{|c|}{$\begin{array}{l}\text { Nuclear } \\
\text { generation) }\end{array}$} & \multicolumn{2}{|c|}{ Renewables } & \multicolumn{2}{|l|}{ CCS } & \multicolumn{2}{|c|}{ Electric vehicles } \\
\hline & $\begin{array}{l}\text { Option } \\
1\end{array}$ & $\begin{array}{l}\text { Option } \\
2\end{array}$ & $\begin{array}{l}\text { Option } \\
1\end{array}$ & $\begin{array}{l}\text { Option } \\
2\end{array}$ & $\begin{array}{l}\text { Option } \\
1\end{array}$ & $\begin{array}{l}\text { Option } \\
2\end{array}$ & $\begin{array}{l}\text { Option } \\
1\end{array}$ & $\begin{array}{l}\text { Option } \\
2\end{array}$ \\
\hline Start date & 2001 & & 2001 & 2001 & 2010 & 2014 & 2010 & 2010 \\
\hline Bottleneck phase (years) & 15 & & 2 & 3 & 13 & 17 & 6 & 6 \\
\hline Growth phase (years) & 75 & & 20 & 65 & 8 & 8 & 40 & 40 \\
\hline Maturation phase (years) & 25 & & 15 & 25 & 8 & 8 & 16 & 16 \\
\hline $\begin{array}{l}\text { Maximum market share at the } \\
\text { end of the maturation phase }\end{array}$ & $30 \%$ & 0 & $60 \%$ & $50 \%$ & $80 \%$ & $30 \%$ & $80 \%$ & $25 \%$ \\
\hline
\end{tabular}


Table 4: parameter choices for the two assumptions on low carbon technologies.

\section{References}

Fulton L, Eads G (2004) IEA/SMP model documentation and reference case projection. Tech. rep., URL

http://www.wbcsd.org/web/publications/mobility/smp-model-document.pdf

Grazi F, van den Bergh JCJM and van Ommeren JN (2008). An Empirical Analysis of Urban Form, Transport, and Global Warming. The Energy Journal 29(4), 97-107

Greening L, Greene D and Difiglio C (2000).Energy efficiency and consumption - the rebound effect - a survey. Energy Policy, 28(6):389-401

Grübler, A., Nakićenović, N., Victor, D.G. (1999). Dynamics of energy technologies and global change. Energy Policy 27:5, 247-280.

Holland S (2003).Extraction Capacity and the Optimal Order of Extraction. Journal of Environmental Economics and Management 45(3): 569-588.

IEA (2007).World Energy Outlook 2007.IEA/OECD, Paris, France.

Kaufmann R, Dees S, Karadeloglou P and Sanchez M (2004).Does OPEC matter? An econometric analysis of oil prices. The Energy Journal25(4), 67-90.

Kemp MC. and Van Long N (1980). On Two Folk Theorems Concerning the Extraction of Exhaustible Resources. Econometrica 48 (3) 663-673

LEPII-EPE (2006). The POLES model, Institut d'Économie et de Politique de l'Énergie, Grenoble, France, 12 pp. (http://webu2.upmf-grenoble.fr/iepe/textes/POLES12pJan06.pdf).

Rehrl T and Friedrich R (2006).Modeling long-term oil price and extraction with a Hubbert approach: The LOPEX model. Energy Policy 34(15):2413-2428.

Reynolds DB (1999). The mineral economy: how prices and costs can falsely signal decreasing scarcity". Ecological Economics 31 (1): 155-166. 
Solow R (1956).A Contribution to the Theory of Economic Growth. Quarterly Journal of Economics 70(1): 65-94.

Uhler RS (1976). Costs and supply in petroleum exploration: the case of Alberta. Canadian Journal of Economics 19: 72-90.

Zahavi Y and Talvitie A (1980). Regularities in Travel Time and Money Expenditures. Transportation Research Record 750:13-19 


\section{Annex 2: scenario discovery analysis with different indicators}

We repeat the analysis using a different set of indicators. For future challenges to mitigation, we calculate the GDP losses from a mitigation policy reducing emissions in order to stabilize radiative forcing at a given level (we retain a target at $3.7 \mathrm{Wm}^{-2}$ ). The mitigation policy is a global carbon tax, recycled through transfers to households. For adaptation challenges, we use the share of jobs in agriculture in developing countries. Note that in this analysis, the "equity" driver is absent and we only have 143 scenarios, corresponding to our 143 model runs.

\section{Definition of 5 SSP spaces}

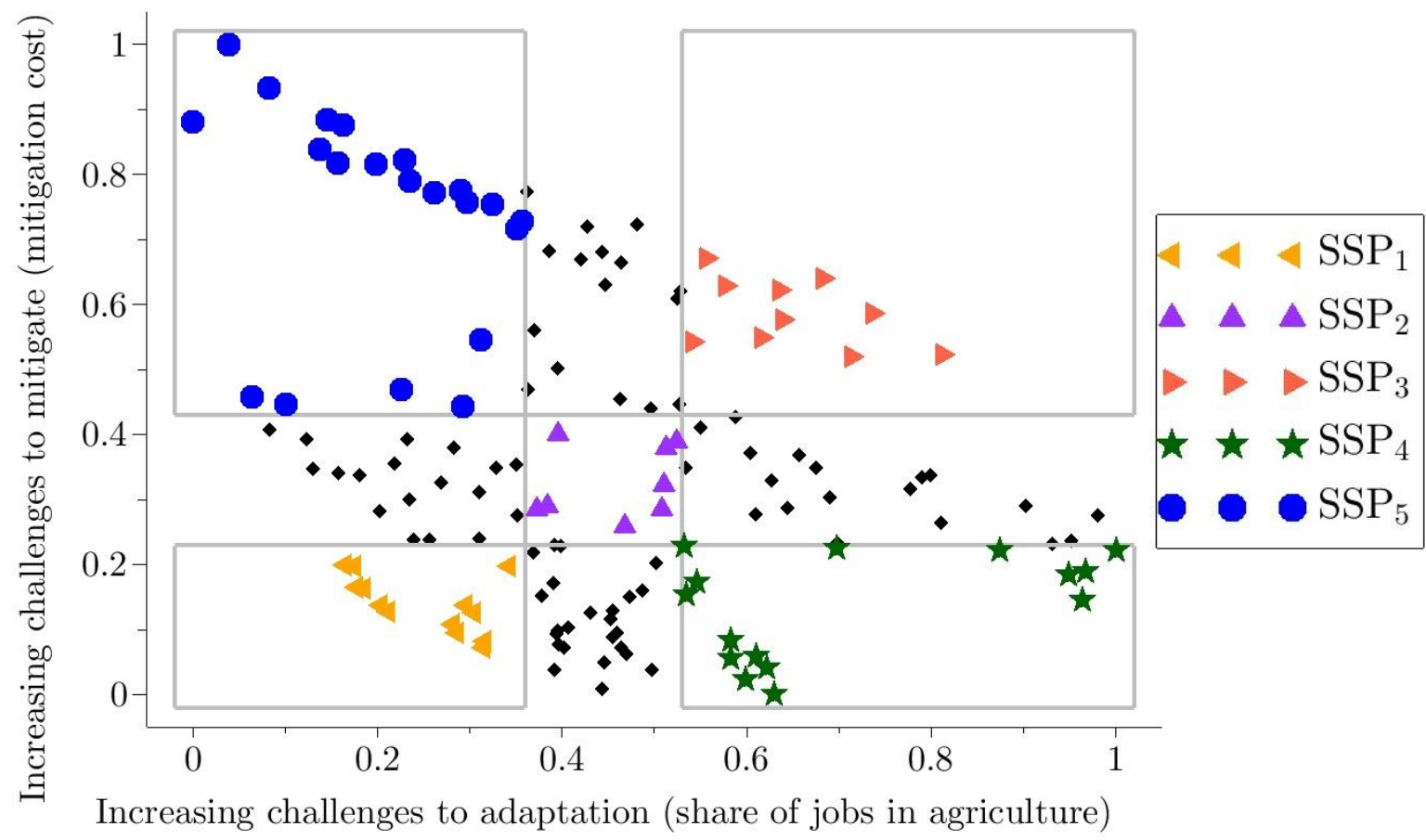

Figure 6: Delimitation of five SSP spaces using different indicators (share of jobs in agriculture in developing countries and GDP losses from a mitigation policy reducing emissions in order to stabilize radiative forcing at a given level).

In Fig. 6, we represent our 143 scenarios in the space delimited by our second set of indicators. We define numerical thresholds for the two mitigation and adaptation challenges indicators that characterize each SSP, the same way as for the first analysis: these thresholds are defined such that one third of the scenarios are below the first threshold and one third of the scenarios are above the second one.

We then repeat the scenario discovery analysis and the results are represented in Table 3. Comparing Table 1 and Table 3, we can see that the results are either similar or complementary. The only contradiction comes from population in SSP2, which is low in the first analysis and medium in the second one. The most important drivers are slightly different: for instance, in the second analysis low carbon technologies are significant for four SSPs while energy sobriety is only significant for three SSPs. 


\begin{tabular}{|c|c|c|c|c|c|c|c|c|}
\hline & $\begin{array}{c}\text { Equity } \\
\text { (2 options) }\end{array}$ & $\begin{array}{l}\text { Conver- } \\
\text { gence } \\
\text { (3 options) }\end{array}$ & $\begin{array}{c}\text { Energy } \\
\text { sobriety } \\
\text { (2 options) }\end{array}$ & $\begin{array}{l}\text { Availability } \\
\text { of low C } \\
\text { technologies } \\
\text { (2 options) }\end{array}$ & $\begin{array}{l}\text { Availability } \\
\text { of fossil } \\
\text { fuels } \\
\text { (2 options) }\end{array}$ & $\begin{array}{l}\text { Population } \\
\text { (3 options) }\end{array}$ & $\begin{array}{c}\text { Capital } \\
\text { markets } \\
(2 \text { options) }\end{array}$ & $\begin{array}{c}\text { Coverage/ } \\
\text { Density }\end{array}$ \\
\hline $\begin{array}{l}\text { SSP1 } \\
\text { (15\% of } \\
\text { cases) }\end{array}$ & & Fast or medium & $\begin{array}{l}\text { high } \\
\text { high }\end{array}$ & $\begin{array}{l}\text { high } \\
\text { high } \\
\end{array}$ & & Mediumorlow & $\begin{array}{l}\text { Reduced } \\
\text { imbalances }\end{array}$ & $50 \% / 80 \%$ \\
\hline $\begin{array}{l}\text { SSP2 } \\
\text { (10\% of } \\
\text { cases) }\end{array}$ & & $\begin{array}{c}\text { medium } \\
\text { Mediumorslow }\end{array}$ & low & & & $\begin{array}{l}\text { medium } \\
\text { low }\end{array}$ & & $30 \% / 60 \%$ \\
\hline $\begin{array}{l}\text { SSP3 } \\
\text { (14\% of } \\
\text { cases) }\end{array}$ & & $\begin{array}{l}\text { Medium } \\
\text { or slow }\end{array}$ & $\begin{array}{l}\text { low } \\
\text { low }\end{array}$ & $\begin{array}{l}\text { low } \\
\text { low }\end{array}$ & & $\begin{array}{l}\text { High or } \\
\text { medium } \\
\text { High ormedium }\end{array}$ & $\begin{array}{l}\text { Reduced } \\
\text { imbalances }\end{array}$ & $55 \% / 90 \%$ \\
\hline $\begin{array}{l}\text { SSP4 } \\
\text { (8\% of } \\
\text { cases) }\end{array}$ & & $\begin{array}{l}\text { slow } \\
\text { slow }\end{array}$ & high & high & & & $\begin{array}{l}\text { Constant } \\
\text { imbalances }\end{array}$ & $90 \% / 85 \%$ \\
\hline $\begin{array}{l}\text { SSP5 } \\
\text { (6\% of } \\
\text { cases) }\end{array}$ & & $\begin{array}{l}\text { fast } \\
\text { fast }\end{array}$ & $\begin{array}{l}\text { low } \\
\text { low }\end{array}$ & low & & & $\begin{array}{l}\text { Reduced } \\
\text { imbalances }\end{array}$ & $60 \% / 45 \%$ \\
\hline
\end{tabular}

Table 3: Combinations of future challenges to adaptation and mitigation for our five SSP spaces as identified by the scenario discovery analysis described in the text. Black/grey text indicates more/less statistically significant drivers. The small italicized text recalls the results in Table 1. Coverage and density measure the explanatory power of the drivers for each SSP. 


\title{
NOTE DI LAVORO DELLA FONDAZIONE ENI ENRICO MATTEI
}

\author{
Fondazione Eni Enrico Mattei Working Paper Series
}

Our Note di Lavoro are available on the Internet at the following addresses:

http://www.feem.it/getpage. aspx?id $=73 \&$ sez=Publications\&padre $=20 \&$ tab $=1$

http://papers.ssrn.com/sol3/JELJOUR_Results.cfm?form_name=journalbrowse\&journal_id=266659 http://ideas.repec.org/s/fem/femwpa.html

http://www.econis.eu/LNG=EN/FAM?PPN=505954494

http://ageconsearch.umn.edu/handle/35978

http://www.bepress.com/feem/

\section{NOTE DI LAVORO PUBLISHED IN 2012}

CCSD $\quad 1.2012 \quad$ Valentina Bosetti, Michela Catenacci, Giulia Fiorese and Elena Verdolini: The Future Prospect of PV and CSP Solar Technologies: An Expert Elicitation Survey

CCSD 2.2012 Francesco Bosello, Fabio Eboli and Roberta Pierfederici: Assessing the Economic Impacts of Climate Change. An Updated CGE Point of View

CCSD $\quad 3.2012$

Simone Borghesi, Giulio Cainelli and Massimiliano Mozzanti: Brown Sunsets and Green Dawns in the Industrial Sector: Environmental Innovations, Firm Behavior and the European Emission Trading

CCSD 4.2012 Stergios Athanassoglou and Valentina Bosetti and Gauthier de Maere d'Aertrycke: Ambiguous Aggregation of Expert Opinions: The Case of Optimal R\&D Investment

CCSD 5.2012 William Brock, Gustav Engstrom and Anastasios Xepapadeas: Energy Balance Climate Models and the Spatial Structure of Optimal Mitigation Policies

Gabriel Chan, Robert Stavins, Robert Stowe and Richard Sweeney: The SO2 Allowance Trading System and the Clean Air Act Amendments of 1990: Reflections on Twenty Years of Policy Innovation

ERM $\quad 7.201$

Claudio Morana: Oil Price Dynamics, Macro-Finance Interactions and the Role of Financial Speculation

ES $\quad 8.2012$

Gérard Mondello: The Equivalence of Strict Liability and Negligence Rule: A « Trompe l'œil » Perspective

CCSD

9.2012

Eva Schmid, Brigitte Knopf and Nico Bauer: REMIND-D: A Hybrid Energy-Economy Model of Germany

CCSD

10.2012

Investmeli and Daniel M. Kammen:

CCSD Investments: Addressing Financing Cost

ERM

$\operatorname{CCSD}$ Importance of Electric Drive Vehicles

13.2012 Ines Österle: Fossil Fuel Extraction and Climate Policy: A Review of the Green Paradox with Endogenous Resource Exploration

ES

14.2012 Marco Alderighi, Marcella Nicolini and Claudio A. Piga: Combined Effects of Load Factors and Booking Time on Fares: Insights from the Yield Management of a Low-Cost Airline

ERM $\quad 15.2012$ Lion Hirth: The Market Value of Variable Renewables

CCSD 16.2012 F. Souty, T. Brunelle, P. Dumas, B. Dorin, P. Ciais and R. Crassous: The Nexus Land-Use Model, an Approach Articulating Biophysical Potentials and Economic Dynamics to Model Competition for Land-Uses

CCSD

Erik Ansink, Michael Gengenbach and Hans-Peter Weikard: River Sharing and Water Trade

CCSD

Carlo Carraro, Enrica De Cian and Massimo Tavoni: Human Capital, Innovation, and Climate Policy: An Integrated Assessment

CCSD

19.2012 Melania Michetti and Ramiro Parrado: Improving Land-use modelling within CGE to assess Forest-based Mitigation Potential and Costs

CCSD

20.2012 William Brock, Gustav Engstrom and Anastasios Xepapadeas: Energy Balance Climate Models, Damage Reservoirs and the Time Profile of Climate Change Policy

ES

21.2012 Alireza Naghavi and Yingyi Tsai: Cross-Border Intellectual Property Rights: Contract Enforcement and Absorptive Capacity

CCSD

22.2012 Raphael Calel and Antoine Dechezleprêtre: Environmental Policy and Directed Technological Change: Evidence from the European carbon market

ERM

23.2012 Matteo Manera, Marcella Nicolini and Ilaria Vignati: Returns in Commodities Futures Markets and Financial Speculation: A Multivariate GARCH Approach

ERM

Alessandro Cologni and
Authoritarian Regimes

ERM

25.2012 Sanya Carley, Sameeksha Desai and Morgan Bazilian: Energy-Based Economic Development: Mapping the Developing Country Context

ES

26.2012 Andreas Groth, Michael Ghil, Stéphane Hallegatte and Patrice Dumas: The Role of Oscillatory Modes in U.S. Business Cycles Regional and Sectoral Effects in a Global CGE Framework 
30.2012 Angelo Bencivenga, Margaretha Breil, Mariaester Cassinelli, Livio Chiarullo and Annalisa Percoco: The Possibilities for the Development of Tourism in the Appennino Lucano Val d'Agri Lagonegrese National Park: A Participative Qualitative-Quantitative Approach

CCSD 31.2012 Tim Swanson and Ben Groom: Regulating Global Biodiversity: What is the Problem?

CCSD 32.2012 J. Andrew Kelly and Herman R.J. Vollebergh: Adaptive Policy Mechanisms for Transboundary Air Pollution Regulation: Reasons and Recommendations

CCSD

33.2012 Antoine Dechezleprêtre, Richard Perkins and Eric Neumayer: Regulatory Distance and the Transfer of New Environmentally Sound Technologies: Evidence from the Automobile Sector

CCSD 34.2012 Baptiste Perrissin Fabert, Patrice Dumas and Jean-Charles Hourcade: What Social Cost of Carbon? A mapping of the Climate Debate

ERM 35.2012 Ludovico Alcorta, Morgan Bazilian, Giuseppe De Simone and Ascha Pedersen: Return on Investment from Industrial Energy Efficiency: Evidence from Developing Countries

CCSD 36.2012 Stefan P. Schleicher and Angela Köppl: Scanning for Global Greenhouse Gas Emissions Reduction Targets and their Distributions

CCSD

37.2012 Sergio Currarini and Friederike Menge: Identity, Homophily and In-Group Bias

CCSD

38.2012 Dominik Karos: Coalition Formation in Generalized Apex Games

CCSD

39.2012

Xiaodong Liu, Eleonora Patacchini, Yves Zenou and Lung-Fei Lee: Criminal Networks: Who is the Key Player?

CCSD

40.2012

CCSD

41.2012 Alizar Allouch: On the Private Provision of Public Goods on Networks

CCSD

42.2012 Efthymios Athanasiou and Giacomo Valletta: On Sharing the Benefits of Communication

CCSD $\quad 43.2012$

Jan-Peter Siedlarek: Intermediation in Networks

CCSD $\quad 44.201$ Matthew Ranson and Robert N. Stavins: Post-Durban Climate Policy Architecture Based on Linkage of Capand-Trade Systems

Valentina Bosetti and Frédéric Ghersi: Beyond GDP: Modelling Labour Supply as a 'Free Time' Trade-off in a

ES

15.2012 Multiregional Optimal Growth Model Liquidated Damages

CCSD 46.2012 Melania Michetti: Modelling Land Use, Land-Use Change, and Forestry in Climate Change: A Review of Major Approaches

CCSD $\quad 47.201$

Jaime de Melo: Trade in a 'Green Growth' Development Strategy Global Scale Issues and Challenges

ERM $\quad 48.2012$ Quest for Energy Security

CCSD Corrado Di Maria, Ian La

CCSD Announcement Effects of the Acid Rain Program

CCSD

Caterina Cruciani, Silvio Giove, Mehmet Pinar

CCSD

CCSD

51.2012 Francesco Nicolli and Francesco Vona: The Evolution of Renewable Energy Policy in OECD Countries: Aggregate Indicators and Determinants

52.2012 Julie Rozenberg, Céline Guivarch, Robert Lempert and Stéphane Hallegatte: Building SSPs for Climate Policy Analysis: A Scenario Elicitation Methodology to Map the Space of Possible Future Challenges to Mitigation and Adaptation 